\title{
EL PRECIO DEL DELITO: DELINCUENCIA Y FISCALIDAD EN LA CIUDAD DE VALENCIA DURANTE EL REINADO DE Alfonso el Magnánimo (1416-1458) SEgún los LIBROS DE CUENTAS DEL JUSTICIA CRIMINAL
}

\author{
Alberto Barber Blasco ${ }^{1}$ \\ Universitat de València
}

Recibido: 11 de mayo de 2020

Aceptado: 24 de diciembre de 2020

\begin{abstract}
Resumen
Estudio social y fiscal sobre los delitos cometidos en la ciudad de Valencia durante el reinado de Alfonso el Magnánimo a través los libros de cuentas del Justicia Criminal y su posterior revisión por parte del Maestre Racional. Se cuantifica el número de delitos que se cometen, quiénes son sus protagonistas, cuáles son las tipologías delictivas y las cantidades económicas que proporcionaban al municipio y a las arcas reales, independientemente de la estructura de otros tribunales en activo (bailía, gobernación, almotacén). Se presenta una aproximación a la criminalidad urbana a través de la acción del Justicia Criminal de Valencia en un periodo determinado por la regularidad de las fuentes documentales.
\end{abstract}

\section{Palabras clave}

Criminalidad; delincuencia urbana; Valencia, siglo XV; justicia medieval.

\section{Resum}

Estudi social i fiscal sobre els delictes realitzats a la ciutat de València durant el regnat d'Alfons el Magnànim a través dels llibres de comptes del Justícia Criminal i la seua posterior revisió per part del Mestre Racional. Es quantifica el nombre de delictes que es cometen, quins són els seus protagonistes, quines són les tipologies delictives i les quantitats econòmiques que proporcionaven al municipi i a les arques reials, independentment de l'estructura d'altres tribunals en actiu (batllia, governació, mostassaf). Es presenta una aproximació a la criminalitat urbana a través de l'acció del Justícia Criminal en un període determinat per la regularitat de les fonts documentals.

\section{Paraules clau}

Criminalitat; delinqüència urbana; València; segle XV; justícia medieval.

\section{Abstract}

Social study about the crimes in the city of Valencia during the Alphonso the Magnanimous reign trough the account books of the Criminal Justice official and him rear revision by the Rational Master. It is

\footnotetext{
1 Universitat de València. Correo electrónico: albertobarberblasco@gmail.com. ORCID: https://orcid. org/0000-0002-6486-8429.
} 
quantified the number of done crimes, who are their protagonists, which are the crime typologies and the economic quantity that provide to the city and to the royal treasure, regardless of the structure of other active tribunals (town hall, government, local police). We present an urban criminality approximation through the Criminal Justice action in a concrete period by the documentary sources regularity.

\section{Keywords}

Criminality; urban crime; Valencia; XVth century; medieval justice.

\section{Introducción ${ }^{2}$}

El estudio de la criminalidad en época medieval continúa siendo a día de hoy un foco de atención que lleva en auge durante las últimas décadas. Los análisis de estos comportamientos sociales han dado lugar a numerosas publicaciones entorno al estudio de fenómenos como la exclusión social en las ciudades, las violencias producidas entre las élites urbanas en forma de bandos, o las diferentes prácticas que la justicia urbana tenía para hacer efectiva su penalización ${ }^{3}$, como investigaciones a escala local a través de las cuáles identificar los delitos punibles. El objetivo de este trabajo es mostrar cuáles eran éstos en un lugar concreto, la ciudad de Valencia, en una cronología específica, el reinado de Alfonso el Magnánimo (1416-1458), para conocer, a través de las fuentes documentales conservadas, cuáles eran las prácticas delictivas más habituales, qué personajes tuvieron un papel relevante y analizar qué repercusiones fiscales tuvieron a través de las multas o composiciones con las que se penaron a los delincuentes.

Este marco de estudio nos permitirá entender, por un lado, las cantidades monetarias que la corona percibía a través de la imposición de estas sanciones y, por otro lado, establecer cuáles eran los crímenes que con mayor frecuencia se registraban en los libros de cuentas, tanto del Justicia Criminal como de su lugarteniente, que se han conservado de manera casi ininterrumpida para la ciudad de Valencia ${ }^{4}$, los cuales

\footnotetext{
Abreviaturas utilizadas: ARV, Archivo del Reino de Valencia; MR, Mestre Racional.

3 Sobre la historiografía de la criminalidad vid. MENDOZA GARRIDO, "La delincuencia a fines de la Edad Media.", pp. 231-259; PÉREZ GARCÍA, "Unas reflexiones en torno a la historia de la criminalidad", pp. 11-37; SEGURA URRA "Raíces historiográficas y actualidad de la historia de la justicia y el crimen en la Baja Edad Media", pp. 577-678; SEgURA URRA "La historia de la delincuencia en la España medieval (1998-2008), pp. 273-338; Sabaté i CuRull, "La pena de muerta en la Cataluña bajomedieval", pp. 117-276. Sobre la exclusión social LóPEz OJEDA (coord.), Los caminos de la exclusión en la sociedad medieval, pecado, delito y represión; CÓRDOBA DE LA LLAVE, "Marginación social y criminalización de las conductas", pp. 293-332. Sobre la lucha de bandos en la Corona de Aragón en el siglo XV vid. Bernabéu BorJA, "L'arbitratge regi a la ciutat de Xàtiva en el context previ a la introducció de la insaculació", pp. 45-71. Sobre delincuencia y conflictos en la Península Ibérica Monsalvo Antón (ed.), Élites, conflictos y discursos políticos en las ciudades bajomedievales de la Península Ibérica; Munita Lonaiz (ed.), Conflicto, violencia y criminalidad en Europa y América; Segura URRa, Fazer justicia: fuero, poder público y delito en Navarra (siglos XIII$X I V$ ); Lojo Piñeiro, A violencia na Galicia do século XV; Mendoza Garrido, Delincuencia y represión en la Castilla Bajomedieval; BazÁn Díaz, Delincuencia y criminalidad en el País Vasco en la transición de la Edad Media a la Moderna.

4 De los libros del Justicia Criminal presentados ante el Maestre Racional se conservan los volúmenes: 6012 , 6013, 6026, 6032, 6034, 6038, 6044, 6047, 6048, 6050, 6051, 6054, 6056, 6058, 6060, 6062, 6067,
} 
muestran en la mayoría de ocasiones, el nombre, apellidos, oficio, la procedencia de los afectados y el delito de los malhechores ${ }^{5}$.

Con este estudio daremos una visión global de la criminalidad a través del papel que tuvieron caballeros, religiosos, judíos, musulmanes y mujeres que aparecieron multados. La manera en que llevaremos a cabo esta tarea será cuantificando y ejemplarizando el número ocasiones en que fueron sancionados, y cuáles fueron las repercusiones fiscales que estas aportaban.

\subsection{El contexto de Valencia en el siglo $X V$}

Los territorios de la Corona de Aragón entraron a partir del siglo XV en un periodo o ciclo expansivo gracias al aumento demográfico, la extensión de los cultivos y el aumento de su productividad. Estos efectos permitieron en última instancia desarrollar las economías urbanas que dieron como resultado un crecimiento económico que se prolongó hasta finales del $\mathrm{XVI}^{6}$. Sin duda alguna, la ciudad que por antonomasia notó este incremento humano fue $V_{a l e n c i a}{ }^{7}$, que se erigió como centro principal de la Corona, incluso por su capacidad financiera al servicio de la monarquía. De modo que, la capacidad de atracción demográfica de Valencia en el periodo reseñado permite contextualizar una constante llegada de migrantes donde no resulta extraño pensar que se manifestasen ciertos conflictos entre los habitantes.

La ciudad de Valencia, durante el siglo XV, ejerció un papel preponderante dentro de la Corona de Aragón y en la Península Ibérica. Este siglo caracterizó al reino valenciano por haber sido una centuria de esplendor artístico y literario traducidos en la expresión de la prosperidad y el dinamismo en el ámbito político y económico. El aumento del número de habitantes de la capital valenciana se debió a la absorción de los recursos humanos del reino, como por haber tenido, además, un puerto muy frecuentado donde otras compañías marítimas hicieron escala en rutas mediterráneas que conectaban con

$6069,6071,6074,6075,6082,6084$; los cuales pertenecen a los años 1416, 1418, 1425, 1428, 1429, 1431, $1434,1436,1437,1439,1440,1441,1442,1443,1444,1448,1449,1450,1451,1452,1456$, respectivamente. Y del lugarteniente de justicia los volúmenes: 6014, 6021, 6023, 6025, 6029, 6033, 6043, 6045, 6046, 6049, 6051, 6053, 6055, 6057, 6059, 6063, 6064, 6065, 6066, 6068, 6070, 6073, 6077, 6081; los cuales pertenecen a los años 1418, 1422, 1423, 1424, 1426, 1428, 1433, 1434, 1435, 1437, 1438, 1439, 1440, 1441, $1442,1444,1445,1446,1447,1448,1449,1450,1452$, respectivamente.

5 Sobre las magistraturas locales de justicia en Valencia vid. PÉrez GArcía, El Justicia Criminal de Valencia (1479-1707); PÉRez GARCíA, Origen y configuración de una magistratura urbana de la Valencia foral: el Justicia Criminal", pp. 21-74; NARbona Vizcaíno, "El Justicia Criminal: una corte medieval valenciana, un procedimiento judicial", pp. 287-310.

6 Iradiel "El segle XV: expansió i crisi en la perspectiva económica", p. 306.

7 Para conocer más aspectos sobre el auge demográfico de Valencia vid. Cueves Granero, "Abastecimientos de la ciudad de Valencia durante la Edad Media", pp. 141-167; Cruselles, Els notaris de la ciutat de València; Santamaría Arández, "La demografia en el contexto de Valencia. Siglo XV.”, p. 363-386; Rubio Vela, "La población de Valencia en la baja Edad Media”, pp. 495-525. 
el Atlántico ${ }^{8}$. Estos factores propiciaron que la Valencia cuatrocentista se convirtiera en una de las ciudades más pobladas de la península y del continente. Esta situación que el reino de Valencia vivió dentro de la Corona de Aragón no fue la misma que la de los otros reinos peninsulares: el Principado de Catalunya entró en un periodo de recesión por la situación de guerra civil debido a la insurrección agraria de los campesinos de remensa y a la pugna entre las facciones del patriciado urbano de Barcelona. El reino de Aragón se caracterizó por su continentalismo agropecuario y por sus intercambios a nivel terrestre con Castilla y con el territorio valenciano, sobre todo a partir de la segunda mitad del cuatrocientos ${ }^{9}$. Como resultado, Valencia se benefició de la crisis catalana porque facilitó la llegada de capital económico y humano de competencia comercial.

De esta manera, la solidez del reino valenciano se acentuó a lo largo del siglo XV y se convirtió, en palabras de Ernest Belenguer, en la capital financera de la monarquia hispànica, capacidad que le permitió sufragar las campañas marítimas del rey gracias al sistema de endeudamiento censal de la ciudad y, al mismo tiempo, erigirse en una ciudad populosa que albergaró en torno a 50.000 almas, hasta que Sevilla, gracias a la conexión directa con las Indias, terminó sustituyéndola como la más poblada de la península ${ }^{10}$. La producción agrícola del territorio valenciano destacó por la caña de azúcar o canyamel, que llamó la atención de compañías toscanas y alemanas; por el arroz de los lugares pantanosos y marjales de Valencia; por la morera, que fomentó la industria sedera, y también por las producciones excelentes de fruta, higos secos, pasas y almendras en poblaciones mudéjares. Por otro lado, se incrementó el número de exportaciones de paños hacia el norte de África, Sicilia y Oriente próximo a través de la conquista del mercado napolitano en tiempos de Alfonso el Magnánimo ${ }^{11}$. Otro aspecto, no menos importante, que mostró este alto nivel económico de la capital valenciana fueron las construcciones arquitectónicas del gótico civil como la Lonja, las Torres de Serranos, el palacio de la Generalitat o el Miguelete, junto a la eclosión cultural de la literatura medieval valenciana a través de la poesía de Ausías March, la prosa de Joan Roís de Corella y la narrativa de Jaume Roig o de Isabel de Villena. Un fenómeno cultural que historiadores y filólogos han calificado a este período bajo el nombre de Siglo de Oro valenciano.

\subsection{Las fuentes del Justicia Criminal y el Maestre Racional}

De las diferentes y numerosas fuentes con las que podemos estudiar la criminalidad contamos principalmente con tres: por un lado, literarias, mediante dietarios y libros de memorias, apuntes notariales marginales, sermones, textos de lírica o narrativa laica y relatos de viajes; por otro lado, legales, como fueros, privilegios y pragmáticas reales;

\footnotetext{
Furió, Història del País Valencià, p. 159.

9 Belenguer, València a la crisi del segle XV, pp. 11-12; Villanueva Morte, "Aragón y Valencia en el siglo XV", p. 140.

10 Belenguer, València a la crisi del segle XV, pp. 13-17; García Marsilla, Historia del arte medieval, p. 251.

11 Belenguer, Los Trastámara, pp. 268-272.
} 
y por último, documentales, a partir de libros de acuerdos municipales, registros de la correspondencia municipal y, en especial, procesos y actuaciones del Justicia Criminal de Valencia, entre los cuáles destacamos los registros fiscales derivados del ejercicio de la justicia, los libros de cuentas del Justicia Criminal ${ }^{12}$, oficial encargado de garantizar el orden y la seguridad necesarias para proteger el vecindario ${ }^{13}$.

Estos libros de cuentas se estructuraban en dos secciones, una de ingresos y otra de gastos. Por un lado están aquellos folios donde se registraron los ingresos o reebudes que el Justicia Criminal recogió a través de las multas impuestas por ciertos delitos, entre los cuales se apuntaron de forma regular las siguientes entradas: el uso de las armas o treyta d'armes, redención de armas o rempçó d'armes, delitos relacionados con la prostitución o fembres públiques, multas impuestas a jugadores de azar, prestamistas y organizadores de timbas bajo el nombre de Dels jochs e dels prestadors e onzeners, delitos referidos a blasfemias bajo la categoría jurar deshonestament de Déu, y por último, una fórmula donde se recogieron diferentes acciones sujetas a penalidad llamada Alcavots e alcavotes, furts, nafres, multes, com d'aquelles que han dos marits $e$ de altres penes. Además, en la misma sección de ingresos se encontraban otras dos entradas económicas que no pertenecían necesariamente a categorías delictivas, como la adjudicación de albalaes para el servicio de guardias, y almonedas de los objectos confiscados y no redimidos, resultado de las ventas de armas confiscadas; por otro lado, estos libros de cuentas nos ofrecen también los gastos o dates, donde aparecen desglosados los pagos a los diferentes oficiales y miembros que formaban parte del cuerpo judicial del municipio como fueron el mismo Justicia Criminal, los trompetas de la ciudad, el verdugo, los sayones, el escribano, los asesores ordinarios, los abogados fiscales del rey, el abogado de los miserables, etc.

Una vez anotados todos aquellos gastos e ingresos por parte del Justicia Criminal estos libros de contabilidad eran presentados como dación de cuentas al Maestre Racional, encargado de revisarlas para computar y recibir los derechos reales. La constitución del oficio del Maestre Racional en el reino de Valencia no fue casual, pues se creó a inicios del reinado de Alfonso el Magnánimo, en 1419, cuando el rey estableció un oficial específico para el reino valenciano, ya que anteriormente existía solamente un único Maestre Racional para toda la Corona de Aragón que actuaba y ejercía su trabajo fiscalizador desde Barcelona. De esta manera, con la instauración de este nuevo magistrado se asistió a un proceso de descentralización de la administración regia. Su aparición y la ampliación de atribuciones consultivas y judiciales se relacionaron con el interés por parte del rey de llevar a cabo un mejor dominio para la conservación y perfeccionamiento en la dirección del patrimonio real, que al mismo tiempo supuso un mayor control sobre los recursos públicos y una vigilancia más férrea de la organización administrativa y financiera de la monarquía. Así, la estructuración del oficio a lo

\footnotetext{
12 Narbona Vizcaíno, "Las fuentes valencianas para la historia de la criminalidad", pp. 350-372.

13 Narbona Vizcaíno, Malhechores, violencia y justícia ciudadana en Valencia bajomedieval, p. 58.
} 
largo del siglo XV convirtió este cargo en uno de los diversos instrumentos de la nueva monarquía para configurar los aparatos de Estado $^{14}$.

De hecho, la creación de un Maestre Racional propio para el reino de Valencia sirvió, en última instancia, para tener un mayor control sobre la gestión económica de todos los oficiales reales, incluido el Justicia Criminal. Con la autoridad contable máxima del reino este nuevo oficial sometía a todos los administradores, recaudadores y tesoreros de las rentas públicas, como a aquellos oficiales capaces de percibir las rentas, derechos y emolumentos incluidos en el real patrimonio. Desde 1420, el Maestre Racional tuvo la competencia exclusiva a la hora de examinar y liquidar la administración de todos aquellos oficiales reales y se convirtió así en una, si no la más importante, instancia de la administración financiera del reino de Valencia, pues su persona sólo podía responder ante el mismo rey ${ }^{15}$. Las muestras que se exponen, pese a su regularidad, no contienen una visión total de la criminalidad urbana durante el reinado de Alfonso el Magnánimo, pues las fuentes con las que contamos, los libros de cuentas del Justicia Criminal y su lugarteniente, pese a que presentan una gran continuidad cronológica no se conservan en paralelo para todos los años:

Figura 1. Libros de cuentas de la justicia criminal (1416-1458).

\begin{tabular}{|l|l|}
\hline$N^{o}$ de libros de cuentas del Justicia Criminal & 23 \\
\hline$N^{o}$ de libros de cuentas del lugarteniente del Justicia Criminal & 24 \\
\hline$N^{o}$ años donde se conservan el libro de cuentas del Justicia Criminal y el de su lugarteniente. & 14 \\
\hline
\end{tabular}

Para el estudio de esta cronología se ha contado con 47 libros de cuentas disponibles de un total de 84, los cuales nos han permitido estudiar 32 de los 42 años de reinado. De estos 32 años sólo 14 nos ofrecen una visión más detallada del número de delitos registrados gracias a la conservación de los libros del Justicia y de su lugarteniente para el mismo año.

Aun así, la observación y estudio de todos ellos nos posibilita conocer una parte la criminalidad de este periodo. Conviene señalar que esta fuente sólo nos puede indicar una "criminalidad media" de la ciudad respecto a los delitos sujetos a una multa o sentencia que incluya una pena pecuniaria ${ }^{16}$. Es decir, se puede cuantificar cuáles fueron los delitos que con mayor frecuencia se produjeron, cuáles de ellos recaudaron un mayor número de ingresos, o dicho de otra de forma, cuáles resultaron ser más beneficios para la corona. Pues de todos los tipos de crímenes que se han mencionado, el rey se reservaba con su capacidad soberana la totalidad de los ingresos que estos proporcionasen, a excepción de los delitos relacionados con el uso violento de armas, de los cuales la ciudad se quedaba con la mitad de sus ingresos y con un tercio de las multas que se

14 Narbona, Muñoz, Cruselles "Las instituciones" p. 276.

15 Pérez García, El Justicia criminal de Valencia (1479-1707), pp. 186-187.

16 Narbona Vizcaíno, Malhechores, Violencia y Justicia Ciudadana en Valencia Bajomedieval, p. 26. 
recaudaron a través de las composiciones por juegos de azar. Por tanto, los ingresos, en su mayoría, iban a parar al tesoro real con los que se habrían de afrontar los gastos de los oficiales y subordinados del ámbito judicial.

\section{Descripción y análisis de la criminalidad urbana}

Como podemos observar en el siguiente gráfico, la evolución de los registros delictivos fue ascendente. El mismo año que la corte real se aposentó en Valencia, a finales de 1425 , se registraron un total de 424 delitos. Una vez instalada, se aprecia una tendencia descendente que siguió hasta llegar al año en que se registró el número mínimo de actividades delictivas, en 1433, con 94 composiciones, siguiendo incluso esta tendencia a la baja unos años más después de que el rey intermitentemente abandonase la ciudad desde finales de 1428. A partir del siguiente año, en 1434, las anotaciones de los delitos iniciaron un periodo al alza llegando a producirse hasta 576 delitos en 1458, último año de reinado de Alfonso el Magnánimo y primeros meses de mandato de Juan II, produciéndose en el año 1444 el número máximo de casos registrados con 970. Este hecho está en relación con el inicio de la lugartenencia de la reina María, esposa del Magnánimo, y el comienzo de una actuación moralizante en la ciudad que afectó al cierre completo del barrio del burdel, o a la represión de todo acto que se considerara como un atentado contra la moral.

Figura 2. Número de infracciones registradas por año en la ciudad de Valencia

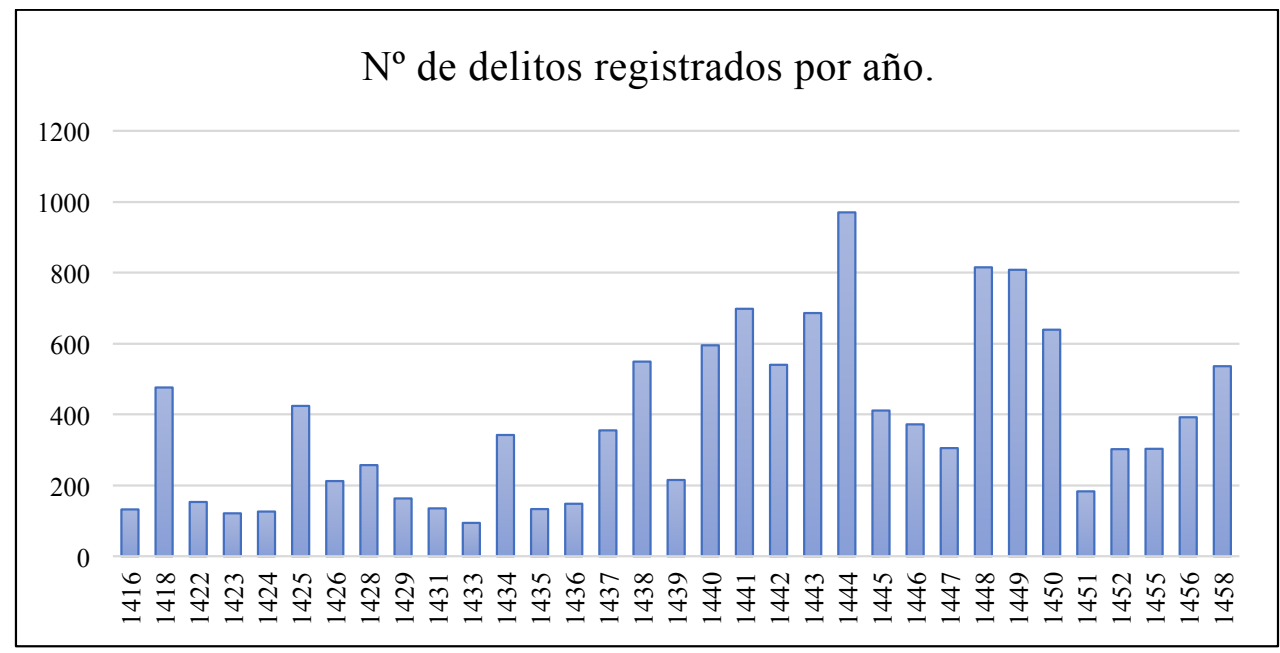

De esta manera, podemos confirmar que la estancia de la corte real resultó clave para la contención de actos punibles y dar una imagen de ciudad relativamente pacífica, 
ilusión que despareció a los pocos años de que la corte abandonase la capital del reino y se incrementara el número de infracciones.

El recuento de las penas que aparecen en los 47 libros nos da como resultado un número total de 12.599 apuntes de sanciones o infracciones. De todos estos, los hombres fueron los que aparecieron con mayor frecuencia multados. Dentro del sexo masculino podemos afirmar que en su mayoría fueron hombres cristianos, pues de los 12.599 casos podemos distinguir: caballeros en 260 ocasiones, eclesiásticos en 127, musulmanes y judíos en 141 y 104 veces respectivamente, a pesar de que estos últimos estaban bajo la jurisdicción del Baile General y no del Justicia Criminal. Por otro lado, 2.142 es el número total de ocasiones en que aparecieron mujeres multadas por el sistema judicial. El recuento final de sanciones según estas tipologías delictivas se distribuye de la siguiente manera:

Figura 3. Número de delitos fsicalizados por categoría delictiva.

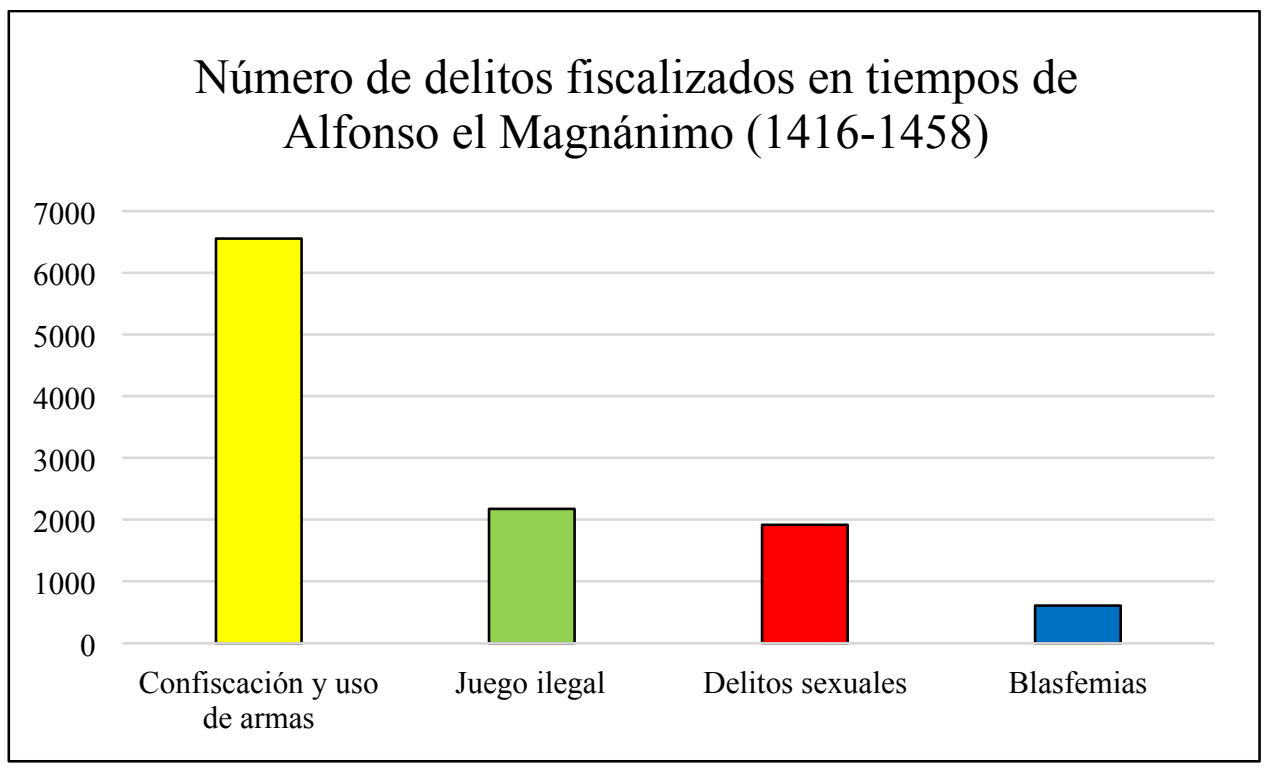

Un primer aspecto a tener en cuenta es que estos resultados no reflejaban una muestra fidedigna o total de los casos, puesto que sólo estamos teniendo en cuenta el número de infracciones que legalmente se registraron por estar sujetos a punición económica, sin conocer por tanto un número real de casos que pudieron producirse o mantenerse fuera de la ley, o condenados a penas corporales. Esta clasificación nos ofrece por tanto una visión un tanto sesgada, aunque, a pesar de ello, puede dar ciertos indicios cualitativos y cuantitativos de las prácticas delictivas de la Valencia cuatrocentista.

De todas las sanciones contabilizadas, 6.545 tuvieron que ver con la confiscación de armas que los sayones realizaban a la población que iba armada como consecuencia 
de su prohibición, los 502 casos restantes estaban relacionados con las amenazas con armas. En segundo lugar, le siguieron los delitos de juego ilegal, de los que se anotaron un total de 2.178 casos; y muy de cerca, los catalogados como delitos sexuales, con un total de 1.920 multas, dentro de las cuales se encuentran delitos como el de barraganía, con 1.239 casos, adulterios, con 607 apuntes, y alcahuetería, con 74 casos. Por último, menos numerosos fueron los delitos referentes a las blasfemias con un total de 612 casos documentados.

Lo primero a destacar de estos resultados fue el predominante número de confiscaciones de armas que se realizaba a la población, con un número total que triplica al segundo número de delitos más multados, el juego. A pesar de que los fueros del reino de Valencia estipularon y restringieron su uso y posesión, y aunque las normativas municipales existentes persiguieran a la gente armada a través de los mecanismos judiciales, su posesión por parte de la población estaba ampliamente extendida y su tenencia formaba parte de la cotidianidad y día a día. En este sentido, la numerosa cantidad de requisas de armas y su posterior venta en las almonedas nos muestra la contradicción que suponía llevar armas dentro de la ciudad cuando estas debían estar custodiadas en las casas, aun así, su dominio entre las diferentes gentes estaba muy extendido. Por este motivo, la actuación punitiva del Justicia Criminal y de su lugarteniente sobre ellas era tan elevada.

De todas las armas que se confiscaron destacaban las siguientes:

Figura 4. Armas más veces requisadas.

\begin{tabular}{|l|l|l|}
\hline Armas confiscadas & Número de apariciones en multas & $\%$ \\
\hline Espadas & 4855 & $80,34 \%$ \\
\hline Escudos & 3636 & $60,16 \%$ \\
\hline Puñales & 1194 & $19,75 \%$ \\
\hline Lanzas & 221 & $3,65 \%$ \\
\hline Cuchillos & 125 & $2,06 \%$ \\
\hline Ballestas & 79 & $1,30 \%$ \\
\hline
\end{tabular}

Como podemos observar, de todas las armas posibles que la población podía tener a su alcance estas eran las más habituales. De todas ellas destacaba la espada, portada en la mayoría de ocasiones junto a un escudo, motivo por el cual éste le sigue en número. Por detrás de estos estaban los puñales, las lanzas, cuchillos y por último las ballestas. Otras armas ofensivas con menor presencia eran los dardos, arcos y arneses; en cambio, entre las defensivas aparecen también corazas, capacetes, gocetes, medias, cotas de malla, avanbrazos, entre otros. De todas las armas que fueron confiscadas o posteriormente vendidas en las almonedas, se observa que algunas de ellas tenían una denominación de origen propia como fueron las lanzas de $\mathrm{Jerez}^{17}$, puñales procedentes

17 ARV, $M R$, vol. 6038, fol. 56v. 
de $\mathrm{Vic}^{18}$, o cuchillos genoveses ${ }^{19}$. Una distinción geográfica que pone de relieve el tráfico comercial armamentístico en el cual la ciudad de Valencia se integraba y que, al mismo tiempo, nos habla de una categorización de las armas en función de su procedencia.

La enorme presencia de las espadas entre las gentes de la ciudad nos demuestra su amplia capacidad de adquisición. A partir de la obra de Hamilton y de su estudio sobre los salarios en Valencia ${ }^{20}$ se pueden constatar que un peón de obra o de albañil necesitaba una media de entre dos y tres días de trabajo para poder adquirir una espada de segunda mano, mientras que una en su estado nuevo costaría entre cinco y siete días laborales. Las ballestas, en cambio, tenían un mayor coste y el esfuerzo laboral que necesitaban para obtenerla era casi la mitad del mes, entre doce y catorce días ${ }^{21}$.

En segundo lugar, cuando hablamos de juego nos estamos refiriendo a los juegos de azar con apuestas dinerarias, los cuales deben entenderse como otro aspecto de cotidianidad que cumple una función lúdica y social de la sociedad medieval. Estos juegos de azar eran el entretenimiento popular por antonomasia en aquel momento a pesar de las reiteradas prohibiciones de los moralistas de la época. Algunos de ellos, como es el caso del valenciano Francesc Eiximenis, a través de su obra Lo crestià, acusaba a los jugadores y ociosos de ser un peligro para la comunidad, dedicándoles el capítulo Com los inútils deuen ésser gitats, e hi deuen ésser sostenguts los pobres mendicants qui són vers indigents ${ }^{22}$. Según san Vicent Ferrer, los ociosos solo podían ser aquellos que no tenían capacidad para ganarse la vida, y por ello debían llevar una señal que los identificara, puesto que algunos malhechores podían simular una incapacidad y robar a los auténticos pobres sus limosnas para apostarlas en las partidas de juego, las cuales solían frecuentarse en tabernas, donde se protagonizaban peleas, se juraba y blasfemaba en nombre de Dios $^{23}$. A pesar de que se intentó paralizar toda clase de juegos y jugadores mediante prohibiciones, descalificaciones, castigos o excomuniones, las condenas permiten comprobar que no tuvieron éxito alguno ${ }^{24}$. La crítica moral y de las disposiciones municipales no redujeron la popularidad de los juegos de azar, puesto que su práctica se realizaba por doquier en diferentes espacios y localizaciones, en plazas, calles, talleres, tiendas, casas u hostales. De todos ellos, la taberna simbolizaba el lugar ideal donde se reunían las gentes de diferentes barrios, amigos y forasteros que iban a pasar la noche, donde se practicaba y estaba presente el juego.

Por último, cabría señalar los delitos sexuales. La prostitución y alcahuetería, atendiendo a las palabras de Francesc Eiximenis, corrompían el sagrado matrimonio a través de los encuentros sexuales de hombres con mujeres extrañas mediante la alcahuetería, la cual

\footnotetext{
18 ARV, MR, vol. 6084, fol. 53v.; A. M. Alcover.; F. de B. Moll (1993), Diccionari català-valencià-balear, Palma, Moll, ved “vigatà". Consultado en: http://dcvb.iecat.net/

19 ARV, $M R$, vol. 6055, fol. 26r.

20 Hamilton, Money, prices, and wages in Valencia, Aragon and Navarre, 1351-1500, pp. 274-277.

21 Faus, La cultura de les armes, p. 83.

22 Eiximenis, Lo crestià, p. 209.

23 Martín Rodríguez, "Los ociosos deberán ser expulsados de la comunidad”, p. 27.

24 GonzÁlez Seara, El laberinto de la fortuna, pp. 78-79.
} 
provocaba como consecuencia la aparición de bastardos que hacían que estos adulterios causasen un gran mal para la Res Publica ${ }^{25}$.

\subsection{Los delitos de los caballeros}

De todos los individuos que fueron registrados en estos libros de cuentas encontramos un abanico variopinto en relación a sus ocupaciones, lugares y condición. De todos ellos vamos a destacar aquellos casos y aspectos más relevantes, como es la reincidencia delictiva entre las gentes de condición más elevada como caballeros y religiosos. Los delitos por los que fueron multados y anotados en la documentación del Justicia Criminal se distribuyen de la siguiente manera:

Figura 5. Número de apariciones de los caballeros en los registros de los libros de cuentas del Justicia Criminal.

\begin{tabular}{|l|l|l|l|}
\hline Delito/Aparición & $N^{o}$ de multas & $\begin{array}{l}\% \text { dentro del } \\
\text { grupo social }\end{array}$ & $\begin{array}{l}\text { \% del número total } \\
\text { de casos }\end{array}$ \\
\hline Requisas y usos de armas & 24 & $9,2 \%$ & $0,36 \%$ \\
\hline $\begin{array}{l}\text { Delitos sexuales } \\
\text { - Barraganía } \\
\text { - Adulterio }\end{array}$ & 17 & $6,53 \%$ & $0,88 \%$ \\
\hline Juego ilegal & 6 & $2,30 \%$ & $0,31 \%$ \\
$4,23 \%$ & $0,57 \%$ \\
\hline Blasfemias & 11 & $68,84 \%$ & $8,21 \%$ \\
\hline $\begin{array}{l}\text { Otros: } \\
\quad \text { Transportar una esclava: }\end{array}$ & 179 & $5,76 \%$ & $2,45 \%$ \\
$\quad$ - No esperar juicio: & 15 & $2,28 \%$ & \\
$\quad-$ No presentarse el día acordado: & 1 & $0,38 \%$ & \\
$\quad$ - Herida: & 1 & $0,38 \%$ & \\
$\quad$ - Estafa: & 1 & $0,38 \%$ & \\
$\quad$ - Hurto: & 1 & $0,38 \%$ & \\
\hline Compra de armas en las almonedas: & 17 & $0,38 \%$ & \\
\hline $\begin{array}{l}\text { Rescate de armas confiscadas por el } \\
\text { Justicia Criminal: }\end{array}$ & 2 & & \\
\hline
\end{tabular}

Si comparamos estos resultados con los estudios realizados sobre el mundo social y delictivo en época medieval podemos comprobar que las dinámicas de comportamiento no eran tan similares. Los estudios de Guido Ruggiero sobre la ciudad de Venecia durante la segunda mitad del XIV y principios de XV nos muestra que los crímenes

25 Eiximenis, Lo crestià, cap. 267, p. 214. 
violentos que con mayor frecuencia cometían los patricios estaban relacionados con las agresiones, mientas que, el número de actos violentos por parte de los valencianos eran ínfimos en el tribunal de la justicia criminal, aunque es posible que fueran más en el del gobernador, a quien correspondía su jurisdicción. En cambio, la violencia y el trato sexual en la capital veneciana ocupaba el segundo puesto, mientras que para los caballeros valencianos ocupaban el tercero ${ }^{26}$.

En la siguiente clasificación se ha comprobado la reiteración de sus actos delictivos relacionados con el juego, ya que de las 260 multas registradas 179 de ellas tenían que ver con este, y de estas vamos a examinar las 149 que se vinculan a la organización de partidas ilegales en sus casas. Este número de timbas estuvieron articuladas entre 10 caballeros: Eximén Pérez de Corella, Pere Roís de Corella, Joan Escorna, Bernat Escorna, Peret Pardo, Lluís Pardo, Martí Çabata, Joan Castella, Francesc Maça y Tristany Pardo, quienes fueron descubiertos en diferentes ocasiones, mientras que Joan Castellà, Bernat Escorna y Tristany Pardo tan sólo se documentan en una ocasión cada uno. Las timbas se organizaron de la siguiente manera:

Figura 6. Número de veces por año que los caballeros organizaron juego en sus casas.

\begin{tabular}{|l|l|l|}
\hline Organizadores de juego & Año & Número de ocasiones \\
\hline Eximén Pérez de Corella $^{27}$ & 1418 & 4 \\
\hline Pere Roís de Corella $^{28}$ & 1449 & 13 \\
& 1450 & 4 \\
& 1452 & 1 \\
& 1456 & 12 \\
& 1458 & 8 \\
\hline Joan Escorna $^{29}$ & 1418 & 5 \\
\hline Peret Pardo $^{30}$ & 1431 & 3 \\
& 1434 & 1 \\
& 1435 & 2 \\
& 1436 & 1 \\
\hline & 1437 & 3 \\
& 1440 & 7 \\
\hline
\end{tabular}

26 Para esta comparación con la ciudad de Venecia nos hemos basado la tabla 5.1 de la obra de RUGGIERO, Patrizi e malfattori, p. 151.

27 ARV, $M R$, vol. 6014, fols. 50r, 55r, 56r, 58v.

28 ARV, $M R$, vol. 6069, fols. 25v, 26r, 26v, 27r, 27v, 28r, 28v, 29r, 29v; ARV, MR, vol. 6071, fols. 17r, 17v, 18r; ARV, $M R, 6073$, fol. 12v; ARV, $M R$, vol. 6077, fol. 20r; ARV, vol. 6082, fols. 28v, 29v, 30r; ARV, $M R$, vol. 6084 , fol. $23 \mathrm{r}, 23 \mathrm{v}, 27 \mathrm{r}$.

29 ARV, $M R$, vol. 6014 , fols. $49 \mathrm{v}, 50 \mathrm{r}, 50 \mathrm{v}, 50 \mathrm{v}, 51 \mathrm{r}$.

30 ARV, $M R$, vol. 6038, fol. 26v, 27r, 29r; ARV, vol. 6044, fol. 33r; ARV, $M R$, vol. 6046, 25r, 28v; ARV, $M R$, vol. 6047, 26r; ARV, $M R$, fol. 6048, fols. 26v, 27r; ARV, $M R$, vol. 6054, fols. 27v, 28r, 28v, 29r, 29v, 30r; ARV, MR, vol. 6057, fols. 23r, 23v, 24r; ARV, vol. 6060, fol. 28v; ARV, vol. 6082, fol. $29 \mathrm{r}$. 
EL PRECIO DEL DELITO: DELINCUENCIA Y FISCALIDAD EN LA CIUDAD DE VALENCIA DURANTE...

\begin{tabular}{|c|c|c|}
\hline Organizadores de juego & Año & Número de ocasiones \\
\hline Peret Pardo & $\begin{array}{l}1441 \\
1443 \\
1456\end{array}$ & $\begin{array}{l}3 \\
1 \\
1\end{array}$ \\
\hline Lluís Pardo ${ }^{31}$ & $\begin{array}{l}1435 \\
1436 \\
1437 \\
1438 \\
1440 \\
1441 \\
1442 \\
1443 \\
1444 \\
1447 \\
1448 \\
1449 \\
1450 \\
1451 \\
1452 \\
1456 \\
1458 \\
\end{array}$ & \begin{tabular}{|l|}
1 \\
3 \\
3 \\
3 \\
10 \\
1 \\
3 \\
2 \\
4 \\
2 \\
1 \\
16 \\
7 \\
1 \\
4 \\
2 \\
4 \\
\end{tabular} \\
\hline Martí Çabata ${ }^{32}$ & $\begin{array}{l}1442 \\
1443\end{array}$ & $\begin{array}{l}6 \\
1\end{array}$ \\
\hline Joan Castellà $^{33}$ & 1418 & 1 \\
\hline Bernat Escorna ${ }^{34}$ & 1418 & 1 \\
\hline Francesch Maça $^{35}$ & $\begin{array}{l}1438 \\
1440 \\
1448 \\
\end{array}$ & $\begin{array}{l}1 \\
1 \\
1 \\
\end{array}$ \\
\hline Tristany Pardo ${ }^{36}$ & 1458 & 1 \\
\hline
\end{tabular}

Con esta tabla se puede observar la implicación que tuvieron los caballeros en las prácticas ilegales del juego, viendo como algunos de ellos trataron de tener una mayor

31 ARV, $M R$, vol. 6046 , fol. $28 \mathrm{v}$; ARV, $M R$, vol. 6047 , fol. 26r, 28r; ARV, $M R$, vol. 6048, fols. 27v, 28r.; ARV, $M R$, vol. 6050, fols. 26r, 26v; ARV, $M R$, vol. 6054, fols. 28v, 29r, 29v, 30v; ARV, $M R$, vol. 6055, fols. 16v, 17r, 17v; ARV, $M R$, vol. 6055, fol. 25r; ARV, $M R$, vol. 6058, fol. 20r; ARV, $M R$, vol. 6059, fols. 16v, 18r; ARV, $M R$, vol. 6060, fol. 29r, 29v; ARV, $M R$, vol. 6063, fols. 31r, 31v, 32v; ARV, $M R$, vol. 6066, fols. 14v, 17v; ARV, $M R$, vol. 6068, fol. 43v; ARV, $M R$, vol. 6069, fol. 25r, 25v, 26r, 26v, 27v, 28r, 28v, 29r, 29v, 30r; ARV, $M R$, vol. 6071, fol. 16v, 17r, 17v, 18r; ARV, MR, vol. 6074, fol. 15r; ARV, $M R$, vol. 6077, fol. 20r, 20v, 24v; ARV, $M R$, 1456, fols. 31v; ARV, $M R$, vol. 6084, fol. 23r.

32 ARV, $M R$, vol. 6058, fol. 20r; ARV, $M R$, vol. 6059, fols. 16v, 17r, 17v, 18r; ARV, $M R$, vol. 6060, fol. 28r.

33 ARV, $M R$, vol. $6014,43 \mathrm{v}$.

34 ARV, $M R$, vol. 6014, fol. 50r

35 ARV, $M R$, vol. 6051, fol. 34v; ARV, $M R$, 6055, fol. 16r; ARV, $M R$, vol. 6068, fol. 40r

36 ARV, $M R, 6084$, fol. $25 \mathrm{v}$ 
presencia o predominio a la hora de organizar estas partidas y que, a pesar de las sanciones económicas que les impusieron, parece que les resultaba más beneficioso económicamente seguir delinquiendo y pagar las multas que dejar de organizar estas timbas. Su participación y competencia era tal que llegaron a copar buena parte de las multas que recogió el Justicia Criminal para un mismo año, como fueron los casos de Lluís Pardo y de Pere Roís de Corella en 1449, quienes se vieron implicados en 29 de las 71 sanciones por juego. En 1440, los familiares Lluís Pardo y Peret Pardo fueron sancionados en 17 de las 70 multas que el Justicia Criminal y su lugarteniente impusieron. En 1456, Pere Roís de Corella acaparó 12 de las 27 sanciones, y en 1458 se vio implicado en 8 de las 58 sanciones, destacando su aparición como exclusivo organizador de juego entre los meses de octubre a diciembre ${ }^{37}$.

Esta reiterativa aparición de los caballeros cometiendo delitos relacionados con el juego estuvo relacionada con el afianzamiento que vino dándose por una cultura inspirada en los tradicionales modelos corteses que se desarrollaron entre los siglos XIV y XV, entre los cuales destacaban el juego de cartas y dados. Estas nuevas prácticas estaban en consonancia con la nueva connotación que los domicilios de esta clase media-alta empezaron a utilizar para socializar, en los que patios y jardines pasaron a convertirse en lugares de recepción, relación y hospitalidad. De esta manera, la casa bajomedieval en los ambientes medios y elevados dejó de ser una casa cerrada y reservada para pasar a ser un espacio más abierto ${ }^{38}$, dando lugar a la articulación de partidas organizadas por estos nobles en sus salones en los que concurrían personas del mismo y diferente grupo socio-económico a probar su suerte.

Por otro lado, el segundo tipo de delito en que destacaron los caballeros giraba en torno al mundo de la prostitución. De las 266 sanciones en 17 de ellas aparecieron multados por cometer delitos sexuales, destacando en primer lugar el adulterio, constatado en 11 ocasiones, seguido de la barraganía, con 6 apuntes. Aquellas relaciones breves entre soltero y prostituta no suponían en principio un riesgo para la paz conyugal de los matrimonios. Su ejercicio evitaba que la lujuria de los no casados se desviase hacia otros pecados que amenazaran las alianzas matrimoniales con adulterios. La prostitución estaba mediatizada por las estructuras de reproducción familiar y por la economía, y por tanto fue una actividad lucrativa en la que el dinero, el poder y la sexualidad se presentaban interrelacionados ${ }^{39}$.

\subsection{Los delitos de los religiosos}

En el apartado de los delitos realizados por miembros de la Iglesia se han contabilizado un total de 127 casos en los que aparecieron implicados sacerdotes, frailes, capellanes, etc. Estos sobresalen por aparecer cometiendo el siguiente número de infracciones:

\footnotetext{
ARV, $M R$, vol. 6084, fol. 27r.

8 Tuliani, "Diversión y ocio en las ciudades italianes de la Baja Edad Media", pp. 120-121.

39 López Beltrán, "La prostitución consentida y la homosexualidad reprimida”, p. 147.
} 
Figura 7. Número de delitos realizados por religiosos.

\begin{tabular}{|l|l|l|c|}
\hline Delito & Número de infracciones & $\%$ dentro del grupo social. & $\%$ total \\
\hline $\begin{array}{l}\text { Confiscación y uso de } \\
\text { armas }\end{array}$ & 14 & $11,02 \%$ & $0,21 \%$ \\
\hline Juego ilegal & 8 & $6,29 \%$ & $0,36 \%$ \\
\hline $\begin{array}{l}\text { Delitos sexuales: } \\
\text { - Barraganía }\end{array}$ & 95 & $74,80 \%$ & $4,94 \%$ \\
- Adulterio & 69 & $54,33 \%$ & \\
- Alcahuetería & 25 & $19,68 \%$ & \\
\hline Blasfemia & 1 & $0,75 \%$ & $0,16 \%$ \\
\hline $\begin{array}{l}\text { Compra de armas en } \\
\text { almonedas }\end{array}$ & 5 & $0,78 \%$ & - \\
\hline Otros: & $3,93 \%$ & - \\
\hline
\end{tabular}

De todos ellos destaca el número de infracciones relacionado con los delitos sexuales. Desde el siglo XIII el discurso eclesiástico entorno a la prostitución tachó de reprobables y pecaminosas estas relaciones, pero al mismo tiempo era consentida como un mal menor útil dentro de la sociedad ${ }^{40}$. Estos delitos relacionados con la moral sexual fueron condenados por la legislación civil al relacionar pecado y delito, y que se entendía simultáneamente en tres niveles: el moral, como una ofensa a Dios o en forma de pecado; el social o público, como un ataque al bien común de la sociedad; y el personal, como una ofensa a la víctima y a su círculo familiar. A pesar de ello, la convivencia fuera del matrimonio tenía un mayor impacto como adulterio cuando era practicado por hombres y mujeres casados o por célibes con órdenes clericales que si fuese practicado por laicos solteros. Este variado tipo de relaciones fueron consideradas un delito y un pecado que se castigaban a través de la justicia pública con condenas y penas heterogéneas, muchas veces corporales ${ }^{41}$.

A pesar de los sermones de grandes moralistas como san Vicent Ferrer, quien recomendaba a los clérigos vivir de manera casta para evitar ser embaucados por el demonio, evitar el amancebamiento, tener un sirviente masculino en lugar de femenino, evitar la masturbación y cultivar el pensamiento ${ }^{42}$, vemos que el número de veces que las personas religiosas acudieron a mujeres para disfrutar del gozo sexual sobrepasaba de manera contundente los otros tipos de delitos. Otras infracciones en las que se vieron involucrados en menor medida eran los relacionados con la confiscación y el uso de armas. Esta familiaridad con el armamento estaba generalizada entre toda la población debido a la cultura de la violencia que se practicaba en esta época, donde la brutalidad estaba vinculada con la manera de relacionarse ${ }^{43}$. Lo mismo podemos decir de

\footnotetext{
40 López Beltrán, "La prostitución consentida y la homosexualidad reprimida", p. 146.

41 Córdoba de la Llave, "Los caminos de la exclusión en la sociedad medieval" pp. 23-26.

42 Narbona Vizcaíno, Pueblo, poder y sexo, p. 102.

43 Muchembled, Una historia de la violencia, pp. 66-73.
} 
su aparición en partidas de juegos de azar, siendo estos como uno de los principales motores de sociabilidad entre la gente de todos los sectores sociales dada su enorme popularidad, donde algunos miembros de la iglesia se integraban y al mismo tiempo se veían implicados.

\subsection{Los delitos de los musulmanes}

El oficial encargado de juzgar y sentenciar los problemas que involucrasen tanto a musulmanes como a judíos era el Baile General, dado que su jurisdicción se extendía a todos los aspectos. Entre estos destacaban los delitos que pudieran cometer, especialmente riñas, robos, mutilaciones, muertes etc. ${ }^{44}$, pero la jurisdicción de estos 149 musulmanes que se vieron envueltos en estas transgresiones concernía a la jurisdicción ciudadana del Justicia Criminal:

Figura 8. Número de apariciones de musulmanes en los libros de cuentas del Justicia Criminal.

\begin{tabular}{|c|c|c|c|}
\hline Delito/aparición & Número de infracciones & $\begin{array}{l}\% \text { dentro del grupo } \\
\text { social }\end{array}$ & $\%$ total \\
\hline Confiscación y uso de armas & 47 & $33,33 \%$ & $0,71 \%$ \\
\hline Juego ilegal. & 15 & $10,63 \%$ & $0,68 \%$ \\
\hline $\begin{array}{l}\text { Delitos sexuales } \\
\text { - Barraganía con mujeres } \\
\text { cristianas } \\
\text { - Adulterio con mujeres } \\
\text { cristianas. }\end{array}$ & $\begin{array}{l}5 \\
3 \\
2\end{array}$ & $\begin{array}{l}3,54 \% \\
2,12 \% \\
1,41 \%\end{array}$ & $0,26 \%$ \\
\hline $\begin{array}{l}\text { Otros: } \\
\text { - Detención en el burdel. } \\
\text { - Peleas. }\end{array}$ & $\begin{array}{l}2 \\
1 \\
1\end{array}$ & $\begin{array}{l}1,41 \% \\
0,70 \% \\
0,70 \%\end{array}$ & - \\
\hline Blasfemias & 1 & $0,70 \%$ & $0,16 \%$ \\
\hline $\begin{array}{l}\text { Compra de armas en } \\
\text { almonedas }\end{array}$ & 71 & $50,35 \%$ & - \\
\hline
\end{tabular}

De esta clasificación sorprende ver la numerosa cantidad de veces que los moros aparecieron en almonedas comprando armas y, en segundo lugar, por el número de veces que fueron detenidos por portarlas sin autorización. La ciudad pretendía que sólo aquellos que se encargaran de preservar la seguridad del municipio pudieran ir armados, independientemente de que la exhibición de armas fuese un elemento distintivo de los

${ }_{44}$ Piles Ros, Estudio documental sobre el Bayle General de Valencia, su autoridad y jurisdicción, pp. 36-39. 
caballeros, pero la realidad era bien distinta, ya que los libros de cuentas nos muestran una visión muy amplia de las personas que iban armadas. Pese a la segregación que padecieron musulmanes y judíos en la ciudad de Valencia, ninguno de los dos grupos vio coartados su acceso a las armas. Y en concreto los musulmanes, quienes a pesar de las sucesivas revueltas que produjeron en la Corona de Aragón, en especial, en el reino de Valencia desde el siglo XIII ${ }^{45}$, o formando parte de los ejércitos del rey Pedro IV en la Guerra de los Dos Pedros ${ }^{46}$, su acceso a las armas no se vio limitado durante la Edad Media hasta que se produjo en tiempos de Felipe II el llamado "desarme de los moriscos" de 1563, momento en que los musulmanes bautizados que aún habitaban en el reino de Valencia fueron verdaderamente desarmados ${ }^{47}$.

Este interés de los musulmanes en la compra de armas debió estar vinculado con su forma de vida, por ser una población que despuntaba entre sus diferentes actividades en el terreno de la manufactura del metal, dedicándose una parte de ellos a los oficios de herrero, calderero o fabricante de escudos. Este tipo de profesión manufacturera la llevaban a cabo a pequeña escala, donde el mismo artesano musulmán era quien comerciaba y vendía sus productos ${ }^{48}$. De esta manera, teniendo en cuenta que las multas referidas a la confiscación de armas eran las más cuantiosas (Fig. 3), se observa que a través su posterior venta existía una verdadera circulación entre el vecindario que al mismo tiempo iban nutriendo las arcas reales a través de las sanciones impuestas por su posesión y su posterior venta ${ }^{49}$.

\subsection{Los delitos de los judios}

Desde mediados del siglo XIV la jurisdicción sobre los judíos, tanto en lo civil como en lo criminal, estuvo en manos del Baile General siempre que los hechos fuesen cuestiones entre judíos; al Justicia Criminal, en cambio, le correspondían aquellas donde se veían involucrados cristianos y judíos ${ }^{50}$. El número de infracciones que cometieron los conversos se desglosan de la siguiente manera:

Figura 9. Número de delitos realizados por judíos.

\begin{tabular}{|l|c|c|c|}
\hline Delito/Aparición & Número de infracciones & \% dentro del grupo social & $\%$ total \\
\hline Requisas y usos de armas & 22 & $21,15 \%$ & $0,33 \%$ \\
\hline Juego ilegal & 53 & $50,96 \%$ & $2,43 \%$ \\
\hline
\end{tabular}

\footnotetext{
45 TORRó, El naixement d'una colònia, pp. 68-72.

46 Lafuente Gómez, “Categorías de combatientes y su armamento en el Aragón bajomedieval”, p. 139.

47 Danvila Collado, "Desarme de los moriscos en 1563", p. 273.

48 Ciscar Pallarés, "Otras actividades económicas. El comercio", p. 249.

49 Narbona Vizcaíno, Malhechores, Violencia y Justicia Ciudadana en la Valencia Bajomedieval, pp. 73-76.

50 Piles Ros, Estudio documental sobre el Bayle General de Valencia, su autoridad y jurisdicción, p. 49.
} 


\begin{tabular}{|c|c|c|c|}
\hline Delito/Aparición & Número de infracciones & $\%$ dentro del grupo social & $\%$ total \\
\hline $\begin{array}{l}\text { Delitos sexuales } \\
\text { - Barraganía con mujeres } \\
\text { cristianas } \\
\text { - Adulterio con mujeres } \\
\text { cristianas }\end{array}$ & $\begin{array}{l}9 \\
5 \\
4\end{array}$ & $\begin{array}{l}8,64 \% \\
4,8 \% \\
3,84 \%\end{array}$ & $0,46 \%$ \\
\hline $\begin{array}{l}\text { Otros: } \\
\text { - Desobedecer } \\
\text { - Peleas } \\
\text { - Hurtos } \\
\text { - Vender esclava } \\
\text { - Azotar }\end{array}$ & $\begin{array}{l}7 \\
1 \\
1 \\
3 \\
1 \\
1\end{array}$ & $\begin{array}{l}6,73 \% \\
0,96 \% \\
0,96 \% \\
2,88 \% \\
0,96 \% \\
0,96 \%\end{array}$ & - \\
\hline Blasfemias & 7 & $6,73 \%$ & $1,14 \%$ \\
\hline $\begin{array}{l}\text { Compra de armas en } \\
\text { almonedas }\end{array}$ & 6 & $5,76 \%$ & - \\
\hline
\end{tabular}

De esta tabla sobresale el número de multas impuestas por juego, las cuales acumulaban la mitad del total de las sanciones aplicadas a este grupo social. La afinidad al juego con apuestas monetarias estuvo muy ligada a la ciudad, especialmente los que eran prohibidos, los cuales eran sancionados por la justicia criminal. Por lo que respecta a la organización de mesas de juego, se observa un amplio abanico social que participaba en él, desde caballeros hasta religiosos, musulmanes, cristianos y judíos, donde encontramos, dado el número de casos, una auténtica cultura lúdica debido a la pasión por el juego de naipes y dados ${ }^{51}$. Un claro ejemplo que muestra este afán se observa en casos como el del converso Daniel Martínez, platero, quien fue multado el 17 de marzo de 1416 con 40 sueldos cuando contravino la obligación a la que se sometió y que quedó registrada en un libro de cédulas donde se comprometió a no jugar ${ }^{52}$.

El juego se desenvolvía al mismo tiempo como un generador de conflictos entre las personas, dando lugar a todo tipo de riñas o encuentros violentos. Además, estas prácticas lúdicas eran perseguidas dentro de la ciudad como bien demuestran los diferentes llamamientos públicos que hacía el trompeta de la ciudad ${ }^{53}$. A pesar de ello, podemos observar que la búsqueda de la erradicación de este tipo de comportamiento se difuminaba, ya que tanto a la ciudad como al monarca les convenían y suponían una continua fuente de ingresos derivada de la persecución judicial de la ludopatía.

El segundo de los delitos en los que más veces se vieron envueltos los seguidores de la fe judaica fueron los relacionados con el uso de las armas debido a diversos factores. El primero de ellos, era que la violencia que se desenvolvía funcionaba como un

\footnotetext{
51 GARCIA-Oliver, Els murs fràgils dels calls, p. 328.

52 ARV, $M R$, vol. 6012, fol. 71v.

53 Narbona Vizcaíno, Malhechores, Violencia y Justicia Ciudadana en la Valencia Bajomedieval, pp. $141-142$.
} 
mecanismo para alcanzar los objetivos de algunas relaciones conflictivas ${ }^{54}$. Otro, era la imagen que estos judíos transmitían como prestamistas, vinculándose con ellos las prácticas usureras que configuraron actitudes y violencias antijudías, propagándose de esta manera cierto recelo hacía este grupo religioso que dificultaba la convivencia entre los miembros de las diferentes religiones ${ }^{55}$. Como también, después de que el peso de su grupo fuera desbancado entre la clase dirigente se convirtió en un grupo social más inerme $^{56}$. Por otro lado, esta violencia protagonizada por judíos se ha detectado tanto entre miembros de la mismo religión y del mismo espacio laboral, como son los casos de los conversos Álvaro de Cuenca y Joan de Zaragoza, ambos sastres, en $1418^{57}$, quienes se vieron involucrados en una amenaza con armas; como siendo ejercida por seguidores de diferentes religiones que ocupaban un mismo puesto laboral, como es el caso del converso Gabriel Pardo, sastre, quien es multado debido a las quejas verbales y por unas heridas denunciadas por Pau Gernos, sastre, y su mujer, en $1418^{58}$. Este tipo de violencia no se daba únicamente dentro de un mismo oficio, también se observan actos impetuosos entre diferentes persones de una misma religión a la hora de atacar a otra persona, como es el caso de Gabriel Maçana, Manuel Valleriola y Daniel Porro, todos ellos conversos, quienes son multados con 275 sueldos por haber herido a Pere Gonbau, labrador de la alquería de Carlet, en $1425^{59}$.

Estos conflictos dentro del mismo espacio laboral se produjeron con frecuencia debido a las condiciones generales del trabajo, donde se generaba un clima social de inseguridad e inestabilidad ${ }^{60}$. Estas actitudes también respondieron al aumento de los procesos de proletarización entre las actividades artesanales, un fenómeno que al mismo tiempo provocaba un aumento de los índices de delincuencia ${ }^{61}$. Y, por último, la implicación de diferentes miembros de una misma religión enfrentados con los miembros de otra fe ponía de relieve la presencia de unos estrechos lazos de solidaridad.

\subsection{Una visión en conjunto de estos grupos sociales}

En estos cuadros comparativos se observan los delitos en los que se vieron involucrados estos grupos sociales, tanto en su categoría individual como a nivel global, en relación con el número total de multas.

En el primero de ellos se observa una fuerte presencia del sector musulmán en aspectos relacionados con las armas, especialmente en las compras realizadas en las almonedas, seguido de las requisas de armas. Un predominio que se vincula a la relación de este

\footnotetext{
Nirenberg, Comunidades de violencia, p. 50.

55 SABAtÉ, "La pena de muerte en la Cataluña bajomedieval", p. 234.

56 Nirenberg, Comunidades de Violencia. pp. 203-223.

7 ARV, MR, vol. 6013, fol. 1r.

ARV, MR, vol. 6014, fol. 3r.

ARV, MR, vol. 6026, fol. 3r

WeIsser, Crime and punishment in Early Modern Europe, p. 54.

${ }_{61}$ Mendoza Garrido, Delincuencia y represión en la Castilla Bajomedieval, p.85.
} 
grupo social con los oficios donde se trabaja con metales y que, al mismo tiempo, pone de relieve la posesión y el uso de las armas de manera generalizada. El segundo aspecto que se demuestra, es el afán desmesurado por los juegos de azar en la ciudad de Valencia debido a los siguientes factores: la amplia sociabilidad que se daba durante el transcurso de las semanas, facilitando así las reuniones para el ocio, destacando como pasatiempo los juegos de naipes, dados y rifas; el acceso a él desde hostales, tabernas y las mesas de juego situadas en el Grao, como su promoción por parte de las clases más acomodadas quienes organizaban timbas en sus salones. A pesar del endurecimiento desde los inicios del siglo XV y, sobre todo, desde la regencia moralizadora de la esposa de Alfonso el Magnánimo, la afición al juego no se revirtió a lo largo de este periodo ${ }^{62}$. Otro aspecto a destacar es el papel de los delitos sexuales. En ellos se vieron involucrados todos los grupos, en mayor o menor medida, debido al gran prestigio nacional e internacional que el burdel de la capital valenciana tuvo durante el siglo XV, y por ello, a una alta densidad de trabajadoras sexuales en las calles quienes trataban de buscar clientes de manera clandestina. Por último, la baja, pero presente, aparición de estos grupos siendo multados por blasfemar, en especial los caballeros y los judíos, pudo estar relacionada con las partidas de juego, en las que también tenían una notoria presencia, donde la fortuna podía hacerles tanto ganar como perder una cuantiosa cantidad de dinero que, acompañado de una desmesurada ingesta de alcohol pudieron dar pie a la pronunciación tanto de insultos, injurias como blasfemias ${ }^{63}$. Pero a pesar del número de multas que les fueron impuestos a estos grupos concretos, ninguno de ellos acaparó de manera global cualquiera de las diferentes categorías delictivas, solamente destacaron de manera ínfima los caballeros en los delitos relacionados con organización de juego y los religiosos en los delitos sexuales.

Figura 10. Cuadro conjunto por categoría social.

\begin{tabular}{|c|c|c|c|c|}
\hline Grupo social & Caballeros & Religiosos & Mudéjares & Judios \\
\hline Requisas y uso de armas & $9,2 \%$ & $11,02 \%$ & $33,33 \%$ & $21,15 \%$ \\
\hline Juego ilegal & $68,84 \%$ & $6,29 \%$ & $10,63 \%$ & $50,96 \%$ \\
\hline Delitos sexuales & $6,53 \%$ & $74,80 \%$ & $3,54 \%$ & $7 \%$ \\
\hline Otros & $2,28 \%$ & $3,13 \%$ & $1,41 \%$ & $6,73 \%$ \\
\hline Blasfemias & $5,76 \%$ & $0,78 \%$ & $0,70 \%$ & $6,73 \%$ \\
\hline Compra de armas en almonedas & $6,5 \%$ & $3,93 \%$ & $50,35 \%$ & $5,76 \%$ \\
\hline
\end{tabular}

62 PÉrez García, La comparsa de los malhechores, pp. 87-92.

63 Gelabertó Vilagrán, "Cuerpo y blasfemia en Cataluña (siglos XV-XVIII), p. 116. 
Figura 11. Cuadro conjunto de las categorías sociales en relación con el número total de multas.

\begin{tabular}{|l|l|l|l|l|}
\hline $\begin{array}{l}\text { Gelito } \\
\text { Grupo social }\end{array}$ & Caballeros & Religiosos & Mudéjares & Judios \\
\hline Confiscación de armas & $0,36 \%$ & $0,21 \%$ & $0,71 \%$ & $0,33 \%$ \\
\hline Juego ilegal & $8,21 \%$ & $0,36 \%$ & $0,68 \%$ & $2,43 \%$ \\
\hline Delitos sexuales & $0,88 \%$ & $4,94 \%$ & $0,26 \%$ & $0,46 \%$ \\
\hline Blasfemias & $2,45 \%$ & $0,16 \%$ & $0,16 \%$ & $1,14 \%$ \\
\hline
\end{tabular}

En su conjunto, la incidencia de estos grupos sobre el total de los casos documentados apenas era notoria. La gran cantidad de gente que durante este periodo era inculpada de cometer una infracción judicial llegaba a ser tan elevada que la aparición de estos otros grupos sociales en comparación pasó casi desapercibida. A pesar de ello, la focalización en estos grupos ha permitido mostrar que, en materia delictiva, estos colectivos, ya fueran de la condición social o religiosa que fueran, estuvieran o no relacionados entre ellos, no estaban exentos de llevar a cabo cierto tipo de comportamientos y actividades perseguidas por la justicia criminal.

\subsection{Los delitos de las mujeres}

Las mujeres que aparecen registradas en las multas impuestas por la justicia criminal pertenecieron mayoritariamente al sector marginal de la sociedad, como prostitutas, algunas esclavas y con la excepción de algunas mujeres casadas. La distribución de sus multas se distribuye de la manera siguiente:

Figura 12. Clasificación de los delitos de las mujeres.

\begin{tabular}{|l|c|}
\hline Delito & $\%$ total \\
\hline Amenaza con armas: & $0,12 \%$ \\
\hline Confiscación de armas: & $0,2 \%$ \\
\hline Delitos sexuales: & $83,89 \%$ \\
- Barraganía & $50,28 \%$ \\
- Adulterio & $24,45 \%$ \\
- Amancebamiento & $7,75 \%$ \\
- Alcahuetería & $1,4 \%$ \\
\hline Organización de juego: & $0,88 \%$ \\
\hline
\end{tabular}




\begin{tabular}{|l|c|}
\hline Delito & \% total \\
\hline Heridas, hurtos y otros: & $15,21 \%$ \\
- Puertas de la cámara abiertas & $6,46 \%$ \\
- Ropaje inapropiado & $3,33 \%$ \\
- Desobediencia & $2,77 \%$ \\
- Peleas & $0,84 \%$ \\
- Hurtos & $0,88 \%$ \\
- Otros & $0,93 \%$ \\
\hline Blasfemia & $0,28 \%$ \\
\hline
\end{tabular}

El predominio de los delitos sexuales que se observa en este sector social responde en gran parte a que la mayoría de las mujeres multadas estaban relacionadas con el mundo de la prostitución. De todos ellos, el más multado fue la práctica de la barraganía, una práctica tolerada como un mal menor y que, a pesar de generalizarse la institución del matrimonio a finales de la Edad Media ${ }^{64}$, continuó siendo el más común entre los diferentes delitos sexuales. El adulterio le siguió como el segundo delito sexual más punido por la justicia criminal, pero en su caso, esta nomenclatura no respondía únicamente al hecho de que fuese la mujer quien mantuviera relaciones sexuales al margen de su matrimonio ${ }^{65}$. En este caso, la fuente judicial señalaba el acto de "adulterar" ${ }^{\prime 6}$ cuando cualquiera de los dos cónyuges estaba casado. En tercer lugar estaba el amancebamiento, una práctica que, a pesar de no gozar del reconocimiento jurídico que garantizaba la barraganía, fue cada vez más perseguida tanto por la legislación civil como eclesiástica $^{67}$. Por último, la alcahuetería fue el delito sexual más minoritario practicado por las mujeres. Un aspecto a destacar es que, a pesar de que la literatura medieval nos ofrece una visión de la alcahuetería como una práctica popular entre las mujeres, la documentación valenciana para esta cronología no se ajustaba a este estereotipo, siendo más números los alcahuetes masculinos que femeninos, igual que ocurría en Barcelona durante la primera mitad del siglo $\mathrm{XV}^{68}$.

Otro motivo por el que fueron perseguidas estas mujeres fue por no acatar las ordenanzas municipales. De todas ellas, la más común fue la de mantener las puertas de sus cámaras abiertas para establecer encuentros con hombres, ejerciendo así una

\footnotetext{
4 BAZÁn DíAz, "El modelo de sexualidad de la sociedad cristiana medieval: norma y transgresión", p. 184 65 Íbidem, p. 188.

66 Alcover.; B. Moll, Diccionari català-valencià-balear, ved “adulteri”. Consultado en: http://dcvb. iecat.net/

67 BAZÁn DíAZ, "El modelo de sexualidad de la sociedad cristiana medieval: norma y transgresión", p. 185.

68 BENito Julià, "La prostitución y la alcahuetería en la Barcelona Bajomedieval (siglos XIV-XV), pp. 9-21.
} 
prostitución clandestina con la finalidad de incrementar sus ingresos ${ }^{69}$. Otra manera de atentar contra la normativa municipal era usando ropas que no eran propias de su oficio, incumpliendo así el reglamento que estipulaban que todas las trabajadoras sexuales debían usar unos atuendos específicos para que fueran identificadas con su oficio. Un ejemplo sobre este tipo de infracción fue el que cometió Jaumina, mujer del burdel, el 28 de junio de 1431, quien fue multada con 22 sueldos por ir vestida como un hombre ${ }^{70}$. Seguidamente, estaban las desobediencias que estas realizaban, entre las cuales destacaban el rechazo a ingresar en las casas de las arrepentidas o de penitencia, como a ser instadas a volver al burdel cuando eran encontradas por la calle. Otro tipo de delito que de manera minoritaria protagonizaban las mujeres fueron robos, como el caso de Merina, mujer del burdel, quien le roba a Pedro de Burgos una bolsa con ocho reales de plata durante el coito ${ }^{71}$. Este tipo de prácticas furtivas fueron frecuentes debido a su escasa remuneración laboral, situación que les impulsaba a cometer este tipo de actos para acrecentar su economía.

Delitos en los que apenas se ha tenido constancia de la presencia femenina fue en el de la organización de juegos de azar y su relación con las armas. Estas timbas estaban copadas casi al completo en los libros de cuentas del Justicia Criminal por hombres, ya fueran caballeros o plebeyos. A pesar de ello, las pocas muestras en las que aparecieron multadas nos hablan del tipo de mujeres que se implicaban en los juegos lúdicos de azar. Estas partidas de juegos eran organizadas principalmente por aquellas que ostentaban el cargo de hostaleras, quienes mediante rifas y juegos buscaban promocionar su negocio para así aumentar el número de asistentes y clientes en sus hostales. De manera aún menos frecuente eran las multas por estar envueltas en trifulcas con otras mujeres. Estos enfrentamientos estaban protagonizados principalmente entre las trabajadoras del burdel, ya que este oficio implicaba la alteración del orden público y podía dar lugar a disputas y reyertas ${ }^{72}$, como fue el caso del 22 de mayo de 1416, donde fueron multadas con 20 sueldos un grupo de mujeres de un burdel por pelearse entre ellas ${ }^{73}$. Otra categoría en la que la presencia femenina era más inferior aún fue en las requisas de armas, como son los casos de Isabel, quien el 28 de mayo de 1456 le fue requisado una ballesta y un cinto, siendo multada por ello con 4 sueldos, y dos días después a otra Ysabel, a la que se les sanciona con 1 sueldo y 6 dineros por requisarle un escudo y una espada ${ }^{74}$. El resto de delitos en los que aparecieron multadas, aunque fueran casi imperceptibles nos demuestra que, en general, por muy diferentes que fueran en número de casos en comparación con los hombres, el espacio del delito no era exclusivo de un sexo u otro, ni que existiera un dominio exclusivo por parte de uno de los dos sexos en alguna de

\footnotetext{
69 Guillot Aliaga, "Mujer y marginación: prostitutas, alcahuetas y concubines en la ciudad de Valencia (s. XIV-XVII)", p. 2030. 
las categorías delictivas, sino que ambos podían desenvolverse y estar imbricados en las diferentes formas de delinquir.

\subsection{La procedencia de las prostitutas}

De los diferentes aspectos que hicieron de Valencia un polo de atracción demográfico cabe señalar que su prostíbulo fue también uno de ellos ${ }^{75}$. La fama del prostíbulo, conocido como La pobla de les fembres peccadrius o el Públich, se expandió no sólo por todos los reinos de la Península Ibérica, también por aquellos territorios cercanos al Mediterráneo y el norte de Europa, compitiendo en renombre al mismo nivel que los grandes centros urbanos italianos ${ }^{76}$. Tales fueron las prácticas en la Valencia del siglo XV, que dotaron, por un lado, de grandes beneficios a hostaleros y taberneros que acapararon esta lucrativa actividad ${ }^{77} \mathrm{y}$, por otro lado, generaron cuantiosos beneficios económicos debido al apogeo de la prostitución reglada en el burdel. ${ }^{78}$

La prostitución en la ciudad de Valencia era una profesión reglamentada e institucionalizada, restringida a la localización del burdel donde los encuentros eran considerados lícitos. Este tipo de actividad no sólo estaba avalado y protegido por el municipio, sino que también contaba con el visto bueno de algunos moralistas eclesiásticos, como san Agustín, quien anunció "quita las prostitutas del mundo y lo llenarás de sodomía", como también santo Tomás de Aquino, quien la aceptaba como un método para evitar otros males mayores ${ }^{79}$. El mismo Francesc Eiximenis recogió en su obra, Lo Crestià, el testimonio de san Agustín, añadiendo que estas mujeres no debían mezclarse con las honradas $^{80}$. Mientras que, la prostitución que se perseguía y castigaba era aquella que no seguía las directrices del consejo municipal, es decir la clandestina ${ }^{81}$. Los delitos sexuales constituyeron una fuente recaudatoria, ya que en los mismos libros de cuentas del Justicia Criminal se especifica al comienzo de la redacción de cada capítulo que los beneficios obtenidos por la persecución de estos delitos le pertenecían íntegramente al rey. La llegada de las mujeres a este oficio es difícil de establecer, dado que las fuentes documentales no nos detallan las circunstancias por las cuales se entraba en las redes de la prostitución. Desde la segunda mitad y finales del siglo XIV se observa que no todas las mujeres que ejercían la prostitución procedían exclusivamente de los estratos

\footnotetext{
75 Sobre la prostitución valenciana durante la Baja Edad Media vid. CARmen Peris, "La prostitución valenciana en la segunda mitad del siglo XIV”, pp. 179-199; CARBoneres, Picaronas y alcahuetes ó La mancebía de Valencia; SANCHO GómEZ, "La prostitución en las actas de la ciudad de Valencia de 1413" pp. 297-304; PÉrez GArcía, "Un aspecto de la delincuencia común en la Valencia pre-agermanada: la "prostitución clandestina", pp. 11-42.

76 Pérez García, "Un aspecto de la delincuencia común en la Valencia pre-agermanada: la "prostitución clandestina” (1479-1516)", p. 12.

77 Carmen Peris, "La prostitución valenciana en la segunda mitad del siglo XIV”, pp. 179-199.

78 Graullera, "El fin del burdel de Valencia (s. XIII al s. XVIII)", p. 358.

79 E. Ponferrada, "Santo Tomás y la legalización de la prostitución" p. 166.

80 Eiximenis, Lo Crestià, p. 155.

81 Narbona Vizcaíno, Malhechores, pp. 142-143.
} 
sociales más pobres o de los espacios marginales, aunque buena parte de ellas recurrieron a él como método de subsistencia. La situación de desamparo, la soledad y la falta de recursos conducía a mujeres de baja condición y a viudas por este camino de supervivencia, siendo la prostitución puntual u ocasional la que evitaba la indigencia, pero abría las puertas al burdel. Incluso, en ocasiones, la entrada en la prostitución era impulsada desde el mismo núcleo familiar para sobrevivir en el límite o margen de la sociedad ${ }^{82}$. Para el caso que nos concierne, se ha vaciado de los libros de cuentas del Justicia Criminal el número total de casos relacionados con la prostitución. Uno de los aspectos que hemos querido resaltar ha sido el de conocer la procedencia de las mujeres. La metodología que hemos hecho servir para establecer su origen o procedencia ha estado determinado por la identificación toponímica que, en ocasiones, acompañaba su nombre, considerando pues esta referencia geográfica como una indicación de su procedencia, dado que, en la mayoría de los burdeles hispanos del siglo XV y XVI la mayor parte de las prostitutas eran conocidas por su gentilicio de origen ${ }^{83}$. Por tanto, como no en todos los registros donde se anotaban los delitos de las prostitutas aparece esta referencia la proporcionalidad es bastante inferior al número total de mujeres documentadas, aunque, por ello, los datos no dejan de ser significativos.

El número de mujeres que se han detectado en la documentación ha sido de 2.142, mientas que, el número de mujeres con conocimiento de su supuesta procedencia ha sido de 282, es decir, que contamos únicamente con el 13,16\% del total. Aun así, esta cifra nos ha permitido conocer, por un lado, el número de infracciones que cometían estas mujeres según su origen y, por otro lado, saber quiénes eran las que infringían la ley en un mayor número de ocasiones.

Figura 13. Número de infracciones de las mujeres según su procedencia geográfica.

\begin{tabular}{|l|l|l|}
\hline Territorio de procedencia & Número infracciones & $\%$ total \\
\hline Aragón & 18 & $6,38 \%$ \\
\hline Valencia & 20 & $7,09 \%$ \\
\hline Cataluña & 17 & $6,02 \%$ \\
\hline Mallorca & 12 & $4,25 \%$ \\
\hline Castilla & 144 & $51,02 \%$ \\
\hline Navarra & 14 & $4,96 \%$ \\
\hline Portugal & 17 & $6,02 \%$ \\
\hline Italia & 25 & $8,86 \%$ \\
\hline Francia & 14 & $4,96 \%$ \\
\hline Europa Central & 1 & $0,35 \%$ \\
\hline
\end{tabular}

2 CARMen Peris, "La prostitución valenciana...," pp. 189-190.

83 Córdoba de la LlaVe, Mujer, marginación y violencia entre la Edad Media y los tiempos modernos, p. 12 . 
La designación geográfica de las mujeres que aparecen multadas está sujeta a dos variables. La primera de ellas, a través de la referencia toponímica exacta del lugar de procedencia como: la çaragoçana, la viscahyna o la napolitana; y la segunda, bajo una nomenclatura territorial de su lugar de origen como puede ser: la castellana, la navarra, la aragonesa, la portoguesa, la galega, la francesa, la valenciana, la catalana, la siciliana o la flamencha. De todas ellas, las mujeres que con mayor frecuencia aparecían multadas eran las procedentes de Castilla, de donde se han identificado las localidades de Sevilla, Córdoba, Bonilla, Toledo, Cuenca, Burgos, Jerez, Alarcón, Úbeda, Zamora, Guadalajara, Murcia, Madrid, Alcaraz, Oviedo, Baeza, Algeciras, Logroño, Uceda, Lorca, Carreño, Valladolid, Carmona y Uclés. En segundo lugar tendríamos la procedencia de aquellas mujeres de los territorios peninsulares y baleares de la Corona de Aragón, donde se distinguen los lugares de Zaragoza, Calatayud y Daroca para el caso de Aragón; Barcelona, Tortosa, Tarragona, Lleida, Canyelles y Palamós para el Principado de Cataluña; Valencia, Xàtiva, Gandía, Orihuela, Godella, Sagunt, Vila-Real, Segorbe, Ruzafa y Morella para el reino valenciano; Mallorca y Mahón para el reino de Mallorca; Corella para el Reino de Navarra; Nápoles y Gonella para Italia; y Aviñón y Perpiñán en la actual Francia. Esta designación de origen de las prostitutas era, como podemos observar, mayoritariamente de procedencia urbana. La introducción de estas mujeres al mundo de la prostitución dentro de las ciudades se debió de producir a raíz de su intento fallido de inserción en el mundo urbano después de emigrar del mundo rural, aunque no se descarta una evidente movilidad interurbana.

Con este abanico de localidades de las que procedían estas mujeres, y teniendo en cuenta que esta es sólo una pequeña muestra del total, se revela la cantidad de mujeres que llegaban a la ciudad. De todas ellas, había algunas que cruzaron la línea de la legalidad y fueron multadas de manera reiterativa, destacando aquellas que mayor reincidencia y más problemas tuvieron con la justicia según las multas secundadas.

Figura 14. Mujeres con mayor reincidencia delictiva.

\begin{tabular}{|l|l|}
\hline Nombre de la delincuente & Número de veces que es multada. \\
\hline María de Bonilla & 14 \\
\hline Joana, la siciliana & 6 \\
\hline Isabel, la portuguesa & 5 \\
\hline Caterina de Sevilla & 5 \\
\hline María, la navarra & 4 \\
\hline Leonor de Sevilla & 4 \\
\hline
\end{tabular}

De todas las mencionadas, María de Bonilla destacó por haber sido la más reincidente siendo multada en catorce ocasiones. La primera vez en 1440 por tener las puertas de 
su cámara abiertas ${ }^{84}$, en 1443 por encontrarse con Ramon de Barreda ${ }^{85}$ y por tener las puertas de su cámara abiertas ${ }^{86}$. En 1448 en cuatro ocasiones: el 21 de febrero ${ }^{87}$; el 1 de abril ${ }^{88}$; a finales de septiembre ${ }^{89}$ por mantener relaciones sexuales fuera del burdel; $\mathrm{y}$ a finales de octubre por adulterar con un pescador llamado Joan Sanxo ${ }^{90}$. En 1449 en tres ocasiones, el 7 de marzo ${ }^{91}$, el 17 de septiembre ${ }^{92}$ cuando se le ordenó volver al burdel, y el 27 de agosto por relacionarse con un hombre casado ${ }^{93}$. Un año más tarde, en 1450 , fue sancionada por adulterio en tres ocasiones, a finales de febrero ${ }^{94}$ y el 16 de abril, con un hombre casado ${ }^{95}$; y el 8 de julio ${ }^{96}$ con un joven sastre. Por último, en 1455 en una ocasión por adulterar con Antoni Fuster el 15 de mayo ${ }^{97}$.

En segundo lugar, tenemos a Joana, la siciliana, multada por primera vez el 5 de enero de 1429 por haber sido amancebada de Pere Marti ${ }^{98}$. Cinco años más tarde, en 1434, en dos ocasiones, el 2 de julio por haber sido amancebada de Joan Pardet ${ }^{99}$ y a principios de julio por haber estado con el escudero Joan Pardo ${ }^{100}$. Tres años más tarde, el 13 de abril de 1437, por haber sido amancebada de Bernat Ros ${ }^{101}$. Después, el 18 de mayo de 1440 por haber cometido adulterio con Bertomeu, de Sevilla ${ }^{102}$; y al año siguiente, el 23 de abril de 1441, fue encontrada adulterando con Gabriel Torrella ${ }^{103}$.

A continuación, fueron multadas Isabel, la portuguesa, y Caterina, de Sevilla, en cinco ocasiones cada una. Isabel apareció sancionada por primera vez en 1449 en tres ocasiones, el $13^{104}$ y $14^{105}$ de junio por haber sido amancebada de Martí Navarro, y el 25 de noviembre por adulterio ${ }^{106}$. Después, en 1450 en dos ocasiones, el 27 de junio por haber sido encontrada en adulterio con Avinyó, campesino de Moncada ${ }^{107}$, y el 16 de

\footnotetext{
84 ARV, $M R$, vol. 6054 , fol. 37v.

ARV, $M R$, vol. 6060, fol. 21r

ARV, $M R$, vol. 6060, fol. 38v.

ARV, $M R$, vol. 6067, fol. 21r.

ARV, $M R$, vol. 6067, fol. 21v.

ARV, $M R$, vol. 6067, fol. 23r.

ARV, $M R$, vol. 6068, fol. 28r.

ARV, $M R$, vol. 6069 , fol. 37r.

ARV, $M R$, vol. 6069 , fol. 42r.

ARV, $M R$, vol. 6070 , fol. $13 \mathrm{v}$.

ARV, $M R$, vol. 6073, fol. 10v.

ARV, $M R$, vol. 6071, fol. 23r.

ARV, $M R$, vol. 6071, fol. 23v.

97 ARV, $M R$, vol. 6081, fol. 21r.

98 ARV, $M R$, vol. 6034, fol. 11r.

99 ARV, $M R$, vol. 6044, fol. 19r.

100 ARV, $M R$, vol. 6045, fol. 18r.

101 ARV, $M R$, vol. 6049, fol. 14v.

102 ARV, $M R$, vol. 6054 , fol. 37v.

103 ARV, $M R$, vol. 6057, fol. 16r.

104 ARV, $M R$, vol. 6069, fol. 22r.

105 ARV, $M R$, vol. 6070, fol. 12r.

106 ARV, $M R$, vol. 6070, fol. 15r.

107 ARV, $M R$, vol. 6071, fol. 16r.
} 
septiembre, por haber fornicado con un hombre ${ }^{108}$; Caterina, de Sevilla, fue multada en todas las ocasiones por amancebamiento: las dos primeras ocasiones en 1425, a mitades de agosto con Joan, de Jerez ${ }^{109}$, y el 4 de diciembre con Joanico, el barbero. El 4 de julio de 1433 con Joan, de Úbeda ${ }^{110}$. El 4 de octubre con el escudero Ferrando, de Salamanca $^{111}$, y a finales de enero de 1441 con el aprendiz Joan Pardo ${ }^{112}$.

Finalmente, tendríamos a María, la navarra, y a Leonor, de Sevilla, quienes fueron multadas cuatro veces cada una: Maria fue multada por amancebamiento en dos ocasiones, el 9 de marzo de 1422 con Jacme Lorenç ${ }^{113}$ y el 23 de enero de 1440 con el carnicero Joan Martorell ${ }^{114}$, y por adulterio en 1444 con el pelaire Pere Sànxez ${ }^{115}$ y el 21 de febrero de 1449 con el herrero Martí Guerau ${ }^{116}$; Leonor fue tres veces sancionada por amancebamiento, el 19 de julio de 1418 con Rodrigo, de Carrión ${ }^{117}$, el 12 de febrero de 1446 con el escudero Bertomeu Argent ${ }^{118}$ y el 17 de abril con un daguero ${ }^{119}$. Y la última, por adulterar el 21 de marzo de 1442 con Nicolau Martínez ${ }^{120}$.

De esta manera, se constata la persecución de la prostitución clandestina por parte de las autoridades, la cual perjudicaba económicamente una de las fuentes de ingresos que recaudaba la hacienda pública mediante la prostitución municipal reglada ${ }^{121}$. Este frecuente recurso al comercio sexual fue utilizado por los hombres casados para desfogarse de su insatisfacción sexual en el matrimonio, evitar el adulterio femenino y el amancebamiento $^{122}$.

Con estos datos, se ha observado cómo se reproducían las multas por adulterio, amancebamiento o proxenetismo, como también se ha podido cuantificar la manera en que estas mujeres pudieron actuar de manera reincidente. Por un lado, tendríamos aquellas mujeres que reincidieron de manera continua en un espacio de tiempo breve entre $1 \mathrm{y}$ 2 años, mientras que, otras mujeres reincidieron en un espacio de tiempo más longevo, entre 10 y 20 años de interludio. Esta diferencia en años podría deberse a lo que Rafael Narbona apuntó como la existencia de unos circuitos interurbanos en la prostitución peninsular, relacionadas directa y ágilmente entre sí, e incluso la existencia de rutas o etapas obligadas en la práctica del oficio ${ }^{123}$. Parece lógico pensar que, mediante esta

\footnotetext{
108 ARV, $M R$, vol. 6073, fol. 11r.

109 ARV, $M R$, vol. 6026, fol. 56v.

110 ARV, $M R$, vol. 6043, fol. 18v.

111 ARV, $M R$, vol. 6045, fol. 22v.

112 ARV, $M R$, vol. 6057 , fol. $14 \mathrm{v}$.

113 ARV, $M R$, vol. 6021, fol. 27v.

114 ARV, $M R$, vol. 6054, fol. 20r.

115 ARV, $M R$, vol. 6063, fol. 21v.

116 ARV, $M R$, vol. 6070, fol. 9v.

117 ARV, $M R$, vol. 6013, fol. 20v.

118 ARV, $M R$, vol. 6065, fol. 10r.

119 ARV, $M R$, vol. 6051, fol. 18r

120 ARV, $M R$, vol. 6058 , fol. $14 \mathrm{v}$.

121 Narbona Vizcaíno, Pueblo, poder y sexo, p. 173.

122 Bazán Díaz, Delincuencia y criminalidad, p. 329.

123 Narbona Vizcaíno, Pueblo, poder y sexo, p. 193.
} 
circulación de prostitutas por los diferentes burdeles, su aparición se produjese en la ciudad de Valencia de manera más intermitente infringiendo la ley.

De las mujeres documentadas que fueron penalizadas no todas tenían porqué pertenecer al burdel. En las urbes populosas no era extraño encontrar mujeres solitarias y libres, carentes de un núcleo familiar que se dedicaban a habitar y mezclarse entre las gentes de la ciudad, trabajando en un oficio de cualificación y remuneración bajos. De estas mujeres no se conocía, en su mayoría, el origen geográfico del cual provenían, y era posible que desde la adolescencia se introdujeran al mundo laboral mediante el servicio doméstico y por las causas que fueren no llegaran a contraer matrimonio. El caso es que estas mujeres gozaban de una libertad de movilidad del que pudieron carecer las vecinas casadas. Su trabajo legal no era incompatible con un estilo de vida más abierto, manteniendo contacto con vecinos y hombres forasteros, de los que pudieron sacar algún provecho mediante sus relaciones amistosas o encuentros sexuales que no tenía que ser precisamente en forma de dinero. A pesar de su presencia en las calles honradas de las ciudades, su paso a la prostitución estaría ligado a la situación de precariedad económica, sobre todo entre las solteras, viudas y viudas virtuales ${ }^{124}$. Mujeres sin un núcleo familiar estable, bajo el control ocasional de algún rufián, que pudieron llegar a ejercer este oficio después de ser violadas, enviudar o estar en situación de pobreza ${ }^{125}$.

\section{La fiscalización de la justicia criminal}

La manera en que estos delitos se han cuantificado no se tradujo paralelamente en la cantidad proporcional de ingresos que estos aportaban a partir del cobro de las multas. Así pues, como podemos observar en el siguiente gráfico, el número de veces en que se realizaba un determinado delito no significaba que estos fueran a ser los más rentables en materia fiscal.

Como podemos observar, a pesar de que los delitos catalogados según los libros de cuentas del Justicia Criminal como delitos de alcahuetería y delitos varios resultaban menos cuantiosos en número, con un total de 1.291 casos, eran los que mayor cantidad económica proporcionaban, puesto que sus multas alcanzaban cuotas más elevadas, alcanzando una recaudación total de unos 59.948 sueldos. Esto se debe a que en estos tipos de infracciones las sanciones económicas que podemos encontrar podían variar más al alza que en otras, pues en esta categoría se encuentran desde acusaciones de alcahuetería, como es el caso de Miquel Sànxez, quien fue sancionado con 7 sueldos y 4 dineros al ser acusado como proxeneta en $1426^{126}$; como de otras más elevadas donde podemos encontrar delitos de sangre como homicidios, como el caso de Vicent Chinchella, labrador de Ruzafa, quien fue multado con un total de 900 sueldos de

\footnotetext{
${ }^{124}$ López Beltrán, "La prostitución consentida y la homosexualidad reprimida", pp. 157-158.

${ }^{125}$ Có́doba de la Llave, Mujer, marginación y violencia entre la Edad Media y los tiempos modernos, p. 12.

${ }^{126}$ ARV, $M R$, vol. 6029, 63v.
} 
sanción por matar a Llorenç Garbeller el 14 de noviembre de $1450^{127}$. Con una recaudación de 58.508 sueldos le siguen los delitos relacionados con la prostitución que se recogían bajo la categoría de mujeres públicas. Las penas económicas que se incluyeron en esta sección podían ser heterogenias -incluso siendo por la misma acusación-, por ejemplo, en un libro de cuentas del mismo año se puede observar que el 7 de julio de 1418 se multó a Joanico de les Coves con 6 sueldos y 8 dineros por haber sido acusado de amancebamiento, y el día 28 del mismo mes fueron sancionados Joan Martí y Úrsola, prostituta, de vivir amancebados, con 99 sueldos y 6 dineros. Además, estas multas podían ascender a una mayor cuantía cuando uno de los acusados, en este caso el hombre, formaba parte o era miembro de la Iglesia, como fue el caso de una multa de 266 sueldos y 8 dineros que se le impuso a una mujer viuda que vivía cerca de la parroquia de San Esteban por haber yacido carnalmente con un capellán ${ }^{128}$.

Figura 15. Ingresos que aportaban las diferentes categorías delictivas según los libros de cuentas del Justicia Criminal. ${ }^{129}$

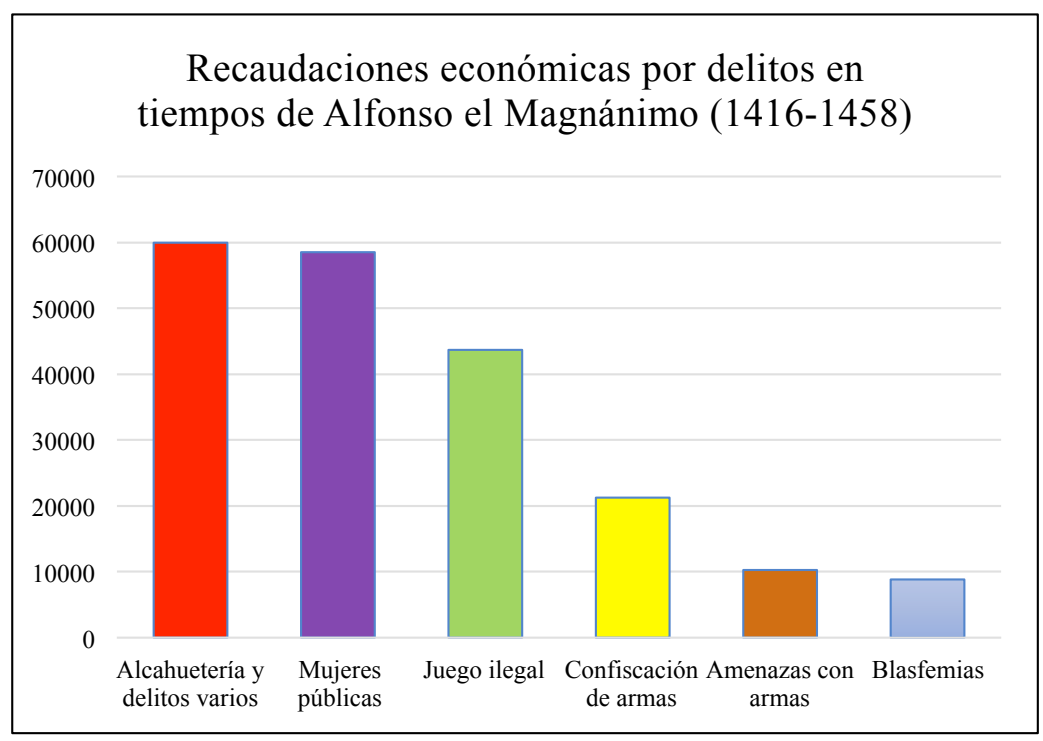

A continuación, seguirían los delitos relacionados con el juego ilegal, los cuales recaudaron unos 43.680 sueldos. En ellos se pueden percibir la diversidad en las multas económicas fijadas si atendemos, por un lado, que los multados fueron meros jugadores de las partidas o si, por otro lado, fueron organizadores de estas timbas. Estas dos formas

\footnotetext{
127 ARV, MR, vol. 6072, 12r.

128 ARV, $M R$, vol. 6013, fol. 23v

129 Expresado en sueldos valencianos. 1 sueldo = 12 dineros; Las categorías aquí expuestas son las correspondientes a las categorías que se utilizan en los mismos libros de cuentas del Justicia Criminal.
} 
de participar en el juego no siempre se diferenciaban, pues se han encontrado personas siendo multadas por 3 sueldos y 6 dineros, como es el caso de Bertomeu Forner un 22 de octubre de $1418^{130}$, y a los dos meses siendo multado con 33 sueldos Joan d'Alvir, labrador de Beniferri, por el mismo motivo ${ }^{131}$. Las sanciones económicas relacionadas con la organización de juego eran por lo general más altas y también diversas entre ellas, como son los casos de un mismo organizador, en este caso, Gabriel Sanç, quien fue multado con 100 sueldos por organizar juego en la casa del noble mosén Pere Pardo el 18 de diciembre de $1434^{132} \mathrm{y}$, antes de acabar el mes, siendo de nuevo sancionado por la misma acción con 668 sueldos ${ }^{133}$.

Respecto a las confiscaciones de armas, a pesar de haber constituido el mayor número de multas su contribución económica rondaba los 21.254 sueldos, mucho menor que las anteriores. En ellas se podían observar variaciones de las cantidades con las que se punía según el número de armas que se portara. Por ejemplo, a Joan Martínez lo multaron con 1 sueldo y 8 dineros por portar una espada y un escudo en enero de $1418^{134}$, mientras que, ese mismo mes, Antoni Bas fue multado por llevar una cota de malla, unas medias de Flandes y una daga con 30 sueldos $^{135}$.

En quinto lugar encontramos las amenazas con armas, las cuales recaudaron una cifra aproximada de unos 10.270 sueldos, y que, por lo general, superaban casi siempre la cifra de 10 sueldos en cada una de las sanciones. A pesar de ello, no estaban exentas de variar al alza. Por ejemplo, tenemos documentado el caso de Luís Martí, platero, quien fue multado con 12 sueldos el 5 de enero de 1425 por enfrentarse en armas a Joan Martínez, barbero ${ }^{136}$, y en agosto del mismo año, encontramos a Bertomeu Calbo, corredor, siendo sancionado por enfrentarse a Joan Martí, tendero, con 55 sueldos ${ }^{137}$.

En último lugar, las blasfemias aportaron una cantidad aproximada de unos 8.832 sueldos. Estas también podían variar en cuánto a su sanción económica a pesar de producirse por el mismo motivo, por ejemplo, Guillem fue multado con 5 sueldos por jurar el jussà o partes bajas de Dios el 6 de junio de 1425, mientras que el 16 de julio del mismo año fue multado con 30 sueldos Miquel Rovira, labrador de Benimaclet, por la misma razón.

Como se aprecia, las sanciones que se impusieron podían ser variables aun siendo denunciados por motivos similares. Esto pudo deberse en parte a la falta de una reglamentación que estableciese una fijación económica en las sanciones judiciales y al arbitrio del Justicia o de la intensidad de los hechos. Ahora bien, el grado de la tasación punitiva posiblemente estaba sujeta a los códigos de honor de la época, el cual podía identificarse en función de su situación social o de si conservaba algún apodo o mal

\footnotetext{
130 ARV, $M R$, vol. 6013, fol. 30v

131 ARV, $M R$, vol. 6013, fol. 32r

132 ARV, $M R$, vol. 6045 , fol. 32r

133 ARV, $M R$, vol. 6045, fol. 32r

134 ARV, $M R$, vol. 6013, fol. 9v.

135 ARV, $M R$, vol. 6013, fol. 10v.

136 ARV, $M R$, vol. 6026, fol. 1r.

137 ARV, MR, vol. 6026, fol. 3v.
} 
nombre que lo identificase con el entorno criminal, pues a través de la reputación individual del malhechor o de su reincidencia las penas podían ir ascendiendo. Por ejemplo, conocemos el caso de Gabriel Sanç, quien el 25 de febrero del año 1434 participó en partidas de juego de azar y fue multado junto a otros personajes no identificados a pagar una sanción de 88 sueldos $^{138}$, y el 22 de diciembre de ese mismo año la multa que se le impuso ascendió a 1.554 sueldos por estar realizando partidas de juego en la casa de un noble durante un período de tiempo comprendido entre 28 y 35 días $^{139}$.

De las diferentes categorías que se han mostrado, podemos observar que aquellas relacionadas con el mundo de la prostitución y el juego fueron las que mayores ingresos aportaban en comparación con el resto de categorías, pues este tipo de delitos tenían como espacio geográfico unos marcos de actuación muy conflictivos como fueron el burdel, donde se hospedaban estas mujeres públicas, y las tabernas y tahurerías, donde se realizaban diferentes juegos como la gresca, nahyps, rifa o canyetes. Estos lugares fueron focos de atracción y espacios ideales donde cometer actos delictivos, dado que en estos sitios se jugaban a juegos prohibidos, se comía, las mujeres concurrían y se bebía en exceso ${ }^{140}$.

Por último, otro factor a tener en cuenta fue el papel moral que tuvieron los vecinos de la ciudad a la hora de contener estas actitudes reprochables por el bien común. En los registros de multas del Justicia Criminal podemos encontrar, en ocasiones, que los acusadores que delataban estos delitos recibían lo terç, una tercera parte de la multa, como compensación. Este tipo de acusaciones se realizaban, en buena medida, contra aquellos comportamientos que provocaban el rechazo de la sociedad. Esta cooperación de la sociedad urbana con la justicia local se efectuaba no sólo porque a través de ella los vecinos obtenían una recompensa económica, sino también para garantizar, al mismo tiempo, el orden, los valores morales y los intereses ciudadanos que se ponían en entredicho con cada una de las infracciones que se cometían ${ }^{141}$. Algunos de estos ejemplos pueden observarse en una pena económica impuesta a Pere Comes de Llíria y a Mayor, mujer de villa, por ser acusados como amancebados con 63 sueldos de los cuales 21 fueron a parar a manos del acusador, quedando un total de 42 sueldos los que la justicia percibió para el rey ${ }^{142}$. Otro caso donde podemos encontrar la cooperación ciudadana en materia judicial fue en las blasfemias. Ramon, el tendero, fue acusado de jurar las partes bajas de Dios con 9 sueldos, llevándose el acusador 1 sueldo y 6 dineros, yendo a parar los restantes 7 sueldos y 6 dineros al tesoro real ${ }^{143}$. En el caso de las blasfemias podemos observar que no siempre se obtenía la tercera parte, sino una cantidad regular de 1 sueldo y 6 dineros. En definitiva, se quiere destacar que se observa un doble interés entre la ciudadanía valenciana, económico y moral, a la hora

\footnotetext{
ARV, $M R$, vol. 6044, fol. 29r.

139 Según el documento durant 4 o 5 setmanes, ARV, MR, vol. 6044, fol. 33r.

140 Narbona Vizcaíno, Malhechores, pp. 135-137.

141 Narbona Vizcaíno, Pueblo, poder y sexo, pp. 140-141.

142 ARV, $M R$, vol. 6069, fol. 20r.

143 ARV, $M R$, vol. 6069, fol. 32v.
} 
de vigilar las acciones punibles por la justicia. Y al mismo tiempo, se pone en evidencia el insuficiente número de miembros integrados en los cuerpos de seguridad que no eran capaces de mantener el orden, dado que se tuvo que recurrir a las solidaridades entre el vecindario y la justicia municipal para la prevención del crimen ${ }^{144}$.

Las cantidades percibidas por parte del Justicia Criminal través de las sanciones no fueron regulares, más bien lo contrario, según el número de libros conservados del Justicia Criminal y del lugarteniente para un mismo año o para años diferentes. La tendencia de ingresos fue mayor o menor, tal y como se puede observar en el siguiente gráfico:

Figura 16. Ingresos del rey y de la ciudad en función de las multas. ${ }^{145}$

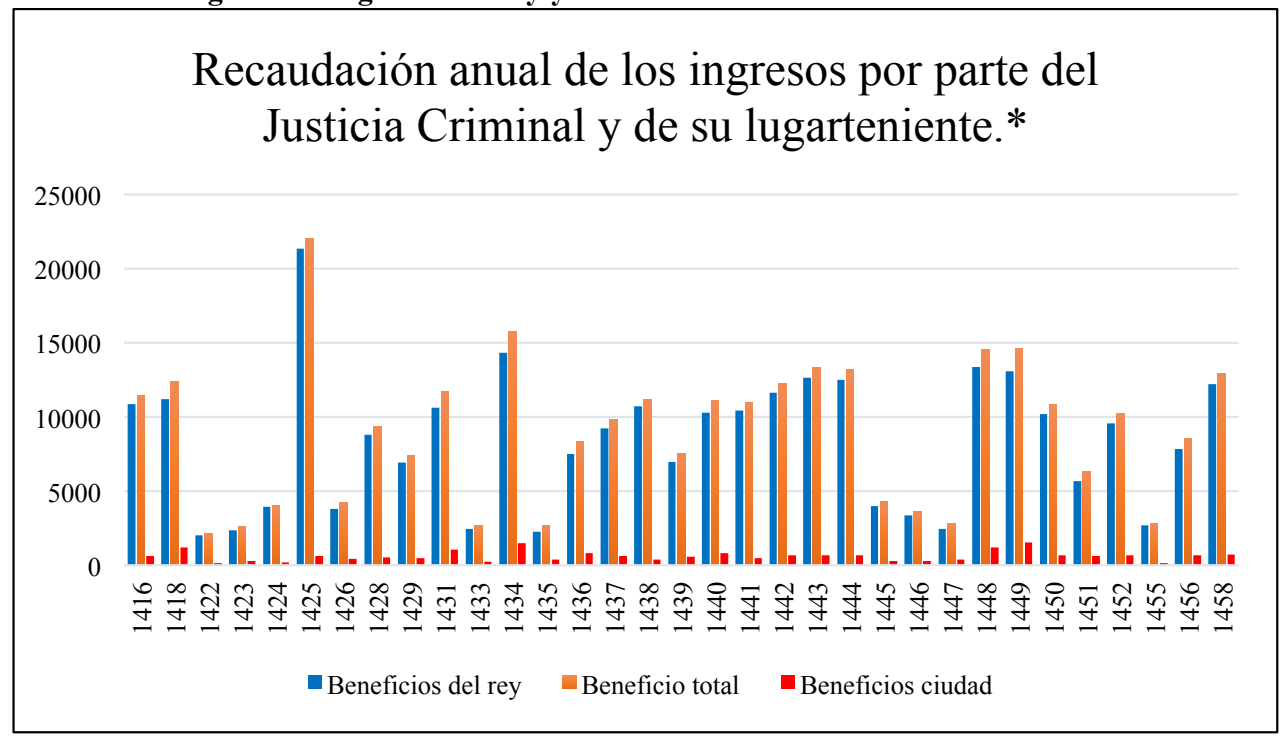

El primer aspecto a destacar de este gráfico es la notable diferencia entre los ingresos que por un lado se llevaba la ciudad y por otro el rey. Como se ha comentado, esta desproporción se debía a que la ciudad sólo podía quedarse con la mitad de los ingresos percibidos de las multas relacionadas con las amenazas con armas, y con un tercio de las composiciones relacionadas con los juegos de azar gracias a los privilegios concedidos por la monarquía, mientras que, la cantidad restante iba directamente al tesoro real.

De esta evolución, llama la atención 1425, el cual aparece en la gráfica representado como el año en que, a pesar de no conservar los ingresos del lugarteniente, se alcanzó el punto máximo con una recaudación aproximada de 22.005 sueldos. Este fenómeno

\footnotetext{
144 CóRdoba de la Llave, "Marginalización social y criminalización de las conductes”, p. 311.

145 Los valores están expresados en sueldos valencianos. 1 sueldo $=12$ dineros.

${ }^{*}$ La distribución de los ingresos entre el rey y la ciudad para el año 1442 es parcial, dado que el capítulo que hace referencia al juego ilegal está incompleto.
} 
pudo estar relacionado directamente con la instalación de la casa y corte real en la ciudad de Valencia a partir del 27 de octubre de 1425, la cual prolongó su estancia en la capital del reino durante aproximadamente unos 4 años y que pese a la ausencia personal del rey la casa mantuvo esta ubicación hasta 1432 . De esta manera, se puede entender que, informada la ciudad de la llegada del rey y su corte para establecerse en la capital del reino, ese mismo año fuese el que mayor número de ingresos produjo la justicia criminal, la cual realizó un gran esfuerzo para perseguir y erradicar el mayor número de delitos. Como consecuencia de esta fuerte represión producida durante el año previo a su estancia, los posteriores años en los que la corte del rey estuvo presente en la ciudad fueron muy inferiores. Así pues, una vez enterados los habitantes de lo que suponía la presencia real en la ciudad, los ingresos provenientes de los delitos que la justicia criminal penaba se vieron reducidos.

El hecho por parte del monarca de trasladar y establecer su corte a la capital valenciana resultó beneficioso tanto para el rey como para la ciudad. Valencia se ofreció a subvencionar con mil florines al soberano por cada mes que este o su corte permanecieran en la capital. Así pues, el rey se benefició económicamente durante el intermedio de sus campañas militares por el mar Mediterráneo y su constante necesidad de capital, y al mismo tiempo, el gobierno municipal valenciano se favorecía del prestigio que le suponía hospedar al monarca, convirtiéndose en el centro político de la Corona. De esta manera, la estancia de la corte real en Valencia potenció el desarrollo de un mercado lujoso a través de sectores artesanales, creando así corrientes comerciales que trajeron beneficios económicos. No obstante, a pesar de los cuatro años de estancia real en la capital, la institución no consiguió incrementar sus ingresos fiscales, pese a que se mejoraron las infraestructuras y se afianzó un mercado de deuda pública que interrelacionó a la ciudad y a su soberano, ligándose de manera firme los intereses de la monarquía y de la clase dirigente local ${ }^{146}$.

Esta recaudación económica a través del sistema de multas no buscaba el acrecimiento de la hacienda regia o municipal, puesto que su aportación representaba tan solo una ínfima parte en comparación con los diferentes mecanismos de fiscalización de la monarquía. De manera similar a otros territorios, esta entrada de ingresos lograba una mayor rentabilidad simbólica que no fiscal, ya que su principal objetivo no era otro que reprimir el desorden público ${ }^{147}$. Este ejercicio económico simbólico se observa claramente en el balance anual de ingresos y gastos de la justicia criminal, el cómputo del cual era casi siempre nulo, ya que con el dinero que se obtenía a través de las sumas proporcionadas por las multas se tenían que costear los salarios y trabajos de aquellos oficiales vinculados al aparato judicial ${ }^{148}$.

146 García Marsilla, "El impacto de la Corte en la ciudad", pp. 291-306.

147 Segura Urra, Fazer justicia: fuero, poder público y delito en Navarra (siglos XIII-XIV), p. 146.

148 BARber Blasco, "Crim i càstig: la criminalitat a la València medieval, al segle XV", pp. 118-123. 


\section{Conclusión}

A partir de estos datos se han podido constatar las diferentes prácticas delictivas en las que se vieron implicados unos grupos sociales concretos. A pesar de la persecución por parte de los moralistas y religiosos del momento, como de las autoridades locales y el sistema judicial, las infracciones por posesión de armas, el juego y los delitos sexuales fueron los más reseñables en la ciudad de Valencia durante este periodo según los libros de cuentas de la justicia criminal..

La numerosa cantidad de multas referidas a la confiscación de armas nos habla de la familiaridad con la que los hombres y, aunque de manera casi inapreciable, mujeres, tenían con estas. Unas cifras que nos hablan de la ineficacia del sistema judicial y de los cuerpos de seguridad encargados de impedir que la gente portase armas en el interior de la ciudad. El asequible acceso a las armas y su posesión garantizaba a la población la acción de defenderse ante un posible enfrentamiento en diferentes lugares y situaciones, ya fuera en una taberna, durante una partida de dados, a la salida de un prostíbulo, como en el interior de las calles para hacer frente a las enemistades locales. Los juegos de azar y apuestas causaban furor entre las diferentes gentes, fuera cual fuera su religión o condición social, sobre todo entre los judíos y los caballeros, jugándose en tabernas, hostales, domicilios propios o en la calle. De estos espacios destacó el papel que tuvieron los caballeros como organizadores de estas timbas, ofreciendo sus casas y salones como lugares de ocio, pudiendo hacer uso de estos convites como un mecanismo más para acrecentar sus ingresos ordinarios, debido a la reiteración en su participación como promotores de estos encuentros a pesar de las multas que les impusieron.

La prostitución femenina vio su desarrollo cenital en las ciudades medievales. La fama del burdel valenciano ya empezó a despuntar desde mediados del siglo XV promoviendo una elevada cantidad de encuentros sexuales de manera clandestina, y que, por tanto, iban en contra de las directrices municipales, las cuales regulaban esta actividad en unos espacios localizados como eran los prostíbulos. A pesar de su persecución por parte de las autoridades municipales y la condena por parte de los religiosos y moralistas, su práctica encubierta acaparó un importante número de infracciones, viéndose en ella implicados hombres de todas las condiciones sociales y de manera muy minoritaria de otras religiones que no fuera la cristiana, de entre los cuales destacaron los religiosos cristianos quienes se vieron implicados en mayor número en delitos de índole sexual que en cualquier otro.

Del mismo modo, se ha intentado presentar una aproximación a la fiscalidad judicial en un periodo concreto, ejemplarizando cuáles fueron las penalidades económicas compuestas según el tipo de delito cometido. Pero como se ha expuesto, a pesar de que el tesoro real retuviera la mayoría de los ingresos a partir del sistema de multas estos no supusieron una importante fuente de ingresos económicos para la hacienda regia en tiempos de Alfonso el Magnánimo. 


\section{Bibliografía}

Asenjo GonzÁlez, María, "La violencia en la sociedad medieval. Revisión, planteamientos y propuestas", La violencia en la sociedad medieval: XXIX Semana de Estudios Medievales, Nájera, del 23 al 27 de julio de 2018, Esther López Ojeda (Coord.) Instituto de Estudios Riojanos, Logroño, 2019, pp. 33-37. https://dialnet.unirioja.es/ servlet/libro?codigo $=737154$

BARBER BlAsco, Alberto, "Crim i càstig: la criminalitat a la València medieval, al segle XV", Mirabilia/Mediterranean and Transatlantic Approaches to the Culture of the Crown of Aragon, 10, 2019, pp. 113-132.

Bas Carbonell, Manuel, Valencia en los libros de viajes, Ajuntament de València, València, 1995. https://dialnet.unirioja.es/servlet/libro?codigo=332394

BAZÁn DíAz, Iñaki, Delincuencia y criminalidad en el País Vasco en la transición de la Edad Media a la Moderna, Departamento de Interior, Servicio Central de Publicacions del País Vasco, Vitoria-Gasteiz, 1995.

BAZÁN DíAz, Iñaki, "El modelo de sexualidad de la sociedad cristiana medieval: norma y transgresión", Cuadernos del CEMYR, 16, 2008, pp. 167-192.

Belenguer, Ernest, Los Trastámara. El primer linaje real de poder político en España, Pasado \& Presente, Barcelona, 2019.

Belenguer, Ernest, València a la crisi del segle XV, edicions 62, Barcelona, 1976. https://dialnet.unirioja.es/servlet/libro?codigo $=86975$

BEnito Julià, Roger. "La prostitución y la alcahuetería en la Barcelona Bajomedieval (siglos XIV-XV)”, Miscelánea medieval murciana, 32, 2008, pp. 9-21.

BernabÉu BorJa, Sandra, "L'arbitratge regi a la ciutat de Xàtiva en el context previ a la introducció de la insaculació", Medievalismo, 27 (2017), pp. 45-71. https://doi. org/10.6018/medievalismo.27.310551

Bonfligio-Dosio, Giorgetta, "Criminalità ed emarginazione a Brescia nel primo Quattrocento”, Archivio Storico Italiano, Florence, $495-496$ (1978) p. 113-164.

Carboneres, Manuel, Picaronas y alcahuetes ó La mancebía de Valencia: apuntes para la historia de la prostitución, El Mercantil Quevedo, Valencia, 1876. https://bivaldi. gva.es/es/consulta/registro.do?id=150

CARmen Peris, María, "La prostitución valenciana en la segunda mitad del siglo XIV, $R e$ vista d'Història Medieval, 1 (1990) pp. 179-199. http://roderic.uv.es/handle/10550/29602 Ciscar Pallarés, Eugenio, "Otras actividades económicas. El comercio" en Entre tierra y fe. Los musulmanes en el reino cristiano de Valencia (1238-1609), Universitat de València, València, 2009, pp. 249-266. https://dialnet.unirioja.es/servlet/articulo?codigo $=2952251$

CóRDOBA DE LA LLAVE, Ricardo, "Marginación social y criminalización de las conductas", El mundo social de Isabel la Católica: la sociedad castellana a finales del siglo XV, Ladero Quesada (Coord.), 2004, pp. 293-332 
Cruselles, Enrique, El Maestre Racional. Función Política y Desarrollo Administrativo del Oficio Público en el siglo XV, Edicions Alfons el Magnànim, València, 1989. https:// dialnet.unirioja.es/servlet/libro?codigo $=172603$

Cruselles, José María, Els notaris de la ciutat de València: activitat professional $i$ comportament social a la primera meitat del segle $X V$, Fundació Noguera, Barcelona, 1998. https://dialnet.unirioja.es/servlet/libro?codigo $=155443$

Cueves Granero, María Amparo, "Abastecimientos de la ciudad de Valencia durante la Edad Media”, Saitabi, 12 (1962) p. 159. http://roderic.uv.es/handle/10550/26548

Danvila Collado, Manuel, "Desarme de los moriscos en 1563”, Boletín de la Real Academia de la Historia, 10 (1887) p. 273-306.

EIXIMENIS, Francesc, Lo crestià, ed. Albert Hauf, Edicions 62, Barcelona, 1994.

Faus Faus, Miquel, La cultura de les armes, Universitat de València. [Trabajo de Fin de Máster inédito], 2017.

Furió I Diego, Antoni, Història del País Valencià, Edicions Tres i Quatre, València, 2001.

García Marsilla, Juan Vicente, "El impacto de la Corte en la ciudad: Alfonso el Magnánimo en Valencia (1425-1428)", El alimento del estado y la salud de la Res Publica: orígenes, estructura y desarrollo del gasto público en Europa, Ángel Galán Sánchez y Juan Manuel Carretero Zamora (eds.), Ministerio de Hacienda y Administraciones Públicas, Instituto de Estudios Fiscales, Madrid, 2013, pp. 291-306. https:/www.academia. edu/5958720/El_impacto_de_la_corte_en_la_ciudad_Alfonso_el_Magn\%C3\%A1nimo_ en_Valencia_1425-1428_en_A._Gal\%C3\%A1n_y_J._M._Carretero_eds._El_Alimento_del_Estado_y_la_salud_de_la_Res_Publica_Or\% $\%$ C $\%$ ADDgenes_estructura_y_desarrollo_del_gasto_p\% $\%$ C3\%Bblico_en_Europa

García Marsilla, Juan Vicente (dir.), Historia del arte medieval, Publicacions Universitat de València, València, 2012. https://dialnet.unirioja.es/servlet/libro?codigo $=577810$ GARCIA-Oliver, Ferran, Els murs fràgils dels calls. Jueus i jueves dels Països Catalans, Editorial Afers, Catarroja, 2019.

Gelabertó Vilagran, Martí, “Cuerpo y blasfemia en Cataluña (siglos XV-XVIII), Revista de dialectologia y tradiciones populares, 68, 1, 2013, pp. 99-123.

González SeAra, Luís, El laberinto de la fortuna: Juego, Trabajo y Ocio en la sociedad espanyola, Biblioteca Nueva, Madrid, 1998. https://dialnet.unirioja.es/servlet/ libro?codigo $=72668$

Graullera, Vicente, "El fin del burdel de Valencia (s. XIII al s. XVIII)”, Mujer, marginación y violencia. Entre la edad media y los tiempos modernos, Ricardo Córdoba de la Llave (coord.), Córdoba, 2006. https://dialnet.unirioja.es/servlet/articulo?codigo=2251492 Guillot Aliaga, María Dolores, "Mujer y marginación: prostitutas, alcahuetas y concubines en la ciudad de Valencia (s. XIV-XVII)", Comercio y cultura en la Edad Moderna: Actas de la XIII Reunión Cientifica de la Fundación Española de Historia Moderna, vol. 2, 2015, 2025-2037. 
Hamilton, Earl J., Money, prices, and wages in Valencia, Aragon and Navarre, 13511500, Philadelphia, Porcupine Press, 1957.

IRADIEL, Paulino, "El segle XV: expansió i crisi en la perspectiva económica", Història de la Corona d'Aragó. L'època medieval (1137-1479), Ernest Belenguer (dir.), I, Edicions 62, Barcelona, 2007, pp. 305-349.

Lafuente Gómez, Mario, "Categorías de combatientes y su armamento en el Aragón bajomedieva: la Guerra de los Dos Pedros (1356-1366)", Gladius: estudios sobre armas antiguas, arte militar y vida cultural en oriente y occidente, 33 (2013), p. 139. http:// gladius.revistas.csic.es/index.php/gladius/article/view/261/266

Lojo Piñeiro, A violencia na Galicia do século $X V$, Universidade de Santiago de Compostela: Servizio de Publicacions E Intercambio Ci, 1991.

LóPEz Beltrán, María Teresa, "La prostitución consentida y la homosexualidad reprimida", Los caminos de la exclusión en la sociedad medieval: pecado, delito y represión, Esther López Ojeda (Coord.), Instituto de Estudios Riojanos, Logroño, 2012, pp. 145170. https://dialnet.unirioja.es/servlet/libro?codigo $=502361$

LóPEz OJEDA, Esther (Coord.) Los caminos de la exclusión en la sociedad medieval, pecado, delito y represión: XXII Semana de Estudios Medievales, Nájera, del 1 al 5 de agosto de 2011, Instituto de Estudios Riojanos, Logroño, 2012. https://dialnet.unirioja. es/servlet/libro?codigo $=502361$

Martín Rodríguez, José-Luís "Los ociosos deberán ser expulsados de la comunidad", Fiesta, juego y ocio en la Historia, Ángel Vaca Lorenzo (ed.), Ediciones Universidad de Salamanca, Salamanca, 2002, pp. 25-78. https://dialnet.unirioja.es/servlet/articulo?codigo $=1018118$

MENDOZA GARRIDO, Juan Miguel, "La delincuencia a fines de la Edad Media. Un balance historiográfico.”, Historia. Instituciones. Documentos, 20 (1993), pp. 231-259. https:// dialnet.unirioja.es/servlet/articulo?codigo $=58290$

Mendoza Garrido, Juan Miguel, Delincuencia y represión en la Castilla Bajomedieval, Grupo Editorial Universitario, Granada, 1999

Monsalvo Antón, José María (ed.), Élites, conflictos y discursos políticos en las ciudades bajomedievales de la Península Ibérica, Ediciones Universidad de Salamanca, Salamanca, 2019. https://dialnet.unirioja.es/servlet/libro?codigo=763165

Muchembled, Robert, Una historia de la violencia. Del final de la Edad Media a la actualidad, Paidós, Barcelona-Buenos Aires-México, 2010.

Munita Lonaiz, José Antonio (ed.), Conflicto, violencia y criminalidad en Europa y América: IV Jornadas de Estudios Históricos del Departamento de Historia Medieval, Moderna y de América, Servicio Editorial de la Universidad del País Vasco, Bilbao, 2004. https://dialnet.unirioja.es/servlet/libro?codigo $=6322$

NARBOna VizCAínO, Rafael, "El justicia criminal: una corte medieval valenciana, un procedimiento judicial”, Estudis castellonencs, 3 (1986), pp. 287-310. https://dialnet. unirioja.es/servlet/articulo?codigo $=156742$ 
Narbona Vizacíno, Rafael, Malhechores, violencia y justicia ciudadana en Valencia bajomedieval (1360-1399), Ajuntament de València, València, 1987. https://dialnet. unirioja.es/servlet/libro?codigo $=137314$

Narbona, Rafael; Muñoz, Rosa; Cruselles, Enrique, "Las instituciones”, Historia del Pueblo Valenciano, en Manuel Cerdá (dir.), I, Levante, 1988, pp. 271-280.

Narbona Vizcaíno, Rafael, Pueblo, poder y sexo. Valencia medieval (1306-1420), Diputació de València, València, 1989. https://dialnet.unirioja.es/servlet/libro?codigo=194358 Narbona Vizcaíno, Rafael, "Las fuentes valencianas para la historia de la criminalidad" en Flocel Sabaté (dir.) L'espai del mal, Pagès editors, Lleida, 2005, pp. 350-372. https:// dialnet.unirioja.es/servlet/articulo?codigo $=2653535$

Narbona Vizcaíno, Rafael, "La Milicia Ciudadana de la Valencia medieval”, Clio \& Crimen, 3 (2006), pp. 305-332. http://www.durango-udala.net/portalDurango/RecursosWeb/DOCUMENTOS/1/0_478_1.pdf

Nirenberg, David, Comunidades de violência. La persecución de las minorías en la Edad Media, Península, Barcelona, 2001.

PÉREz GARCíA, Pablo, “Origen y configuración de una magistratura urbana de la Valencia foral: el Justicia Criminal”, Estudis: Revista d'Història Moderna, 13 (1987), pp. 21-74. https://www.uv.es/dep235/PUBLICACIONS_II/PDF26.pdf

PÉrez García, Pablo, "Unas reflexiones en torno a la historia de la criminalidad", Revista d'Història Medieval, 1 (1990), pp. 11-37

Pérez García, Pablo, El Justicia Criminal de Valencia (1479-1707): una magistratura urbana valenciana ante la consolidación del Absolutismo, Conselleria de Cultura, Educació i Ciència, València, 1991.

PÉrez García, Pablo, "Un aspecto de la delincuencia común en la Valencia pre-agermanada: la "prostitución clandestina” (1479-1516), Revista de Historia Moderna: Anales de Universidad de Alicante, 10 (1991) pp. 11-42. https://www.researchgate.net/publication/39438678_Un_aspecto_de_la_delincuencia_comun_en_la_Valencia_pre-agermanada_la_prostitucion_clandestina_1479-1518

PÉrez García, Pablo, La comparsa de los malechores: Valencia 1479-1518, Centre d'Estudis d'Història Local, València, 1990.

Piles Ros, Leopoldo, Estudio documental sobre el Bayle General de Valencia, su autoridad y jurisdicción, Institució Alfons el Magnànim, València, 1970.

Rubio Vela, Agustín, “La población de Valencia en la baja Edad Media”, Hispania, 190 (1995) pp. 495-525. https://dialnet.unirioja.es/servlet/articulo?codigo=9511

Ruggiero, Guido, Patrizi e malfattori. La violenza a Venezia nel primo Rinascimento, Società editrice il Mulino, Il Mulino, Bologna, 1982.

SABATÉ i Curull, Flocel, "La pena de muerte en la Cataluña bajomedieval", Clío \& Crímen: Revista del Centro de Historia del Crimen de Durango, núm. 4, 2007, pp. 117-276. 
Sancho Gómez, Celia, "La prostitución en las actas de la ciudad de Valencia de 1413", IV Jornades d'Investigació de la facultat de Filosofia i Lletres, Ernesto Cutillas Orgilés (coord.) Universitat d'Alacant, 2015, pp. 297-304.

SANTAMARía ArÁndez, Álvaro, "La demografia en el contexto de Valencia. Siglo XV.", Medievalia, 10 (1992) p. 363-386. https://es.readkong.com/page/la-demografia-en-el-contexto-de-valencia-siglo-xv-1355271

Segura UrRa, Félix, Fazer justicia: fuero, poder público y delito en Navarra (siglos XIII-XIV), Gobierno de Navarra, 2005.

Segura UrRa, Félix, "Raíces historiográficas y actualidad de la historia de la justicia y el crimen en la Baja Edad Media", Anuario de historia del derecho español, 73, 2003, pp. 577-678. https://dialnet.unirioja.es/servlet/articulo?codigo=790276

Segura UrRa, Félix, "La historia de la delincuencia en la España medieval (1998-2008), Medievalismo, 2008, pp. 273-338.

Torró, Josep, La fundació d'una colònia. Dominació i resistència a la frontera valenciana (1238-1276), Publicacions Universitat de València, 2006, pp. 68-72.

Tuliani, Maurizio, "Diversión y ocio en las ciudades italianes de la Baja Edad Media", Fiesta, juego y ocio en la historia, en Ángel Vaca Lorenzo (ed.), Ediciones Universidad de Salamanca, Salamanca, 2003 pp. 103-123.

Villanueva Morte, Concepción, “Aragón y Valencia en el siglo XV: vínculos económicos entre espacios políticos fronterizos", Anales de historia antigua, medieval y moderna, 48 (2014) p. 140. https://dialnet.unirioja.es/descarga/articulo/6076582.pdf

Weisser, Michael R., Crime and punishment in Early Modern Europe, The Harvester Press, Bristol, 1982.

Bibliografia en línea:

https://dcvb.iec.cat/

E. Ponferrada Gustavo, "Santo Tomás y la legalización de la prostitución", https:// www.ancmyp.org.ar [30 de Diciembre de 2019]. 